Does Joint Modelling of the World Economy Pay Off?

Evaluating Global Forecasts from a Bayesian GVAR 
The Working Paper series of the Oesterreichische Nationalbank is designed to disseminate and to provide a platform for discussion of either work of the staff of the OeNB economists or outside contributors on topics which are of special interest to the OeNB. To ensure the high quality of their content, the contributions are subjected to an international refereeing process. The opinions are strictly those of the authors and do in no way commit the OeNB.

The Working Papers are also available on our website (http://www.oenb.at) and they are indexed in RePEc (http://repec.org/).

Publisher and editor

Editorial Board

of the Working Papers

\section{Coordinating editor}

Design

DVR 0031577

ISSN 2310-5321 (Print)

ISSN 2310-533X (Online)

(C) Oesterreichische Nationalbank, 2015. All rights reserved.

Oesterreichische Nationalbank

Otto-Wagner-Platz 3, 1090 Vienna, Austria

PO Box 61, 1011 Vienna, Austria

www.oenb.at

oenb.info@oenb.at

Phone (+43-1) 40420-6666

Fax (+43-1) 40420-046698

Doris Ritzberger-Grünwald, Ernest Gnan, Martin Summer

Martin Summer

Communications and Publications Division 


\title{
Does Joint Modelling of the World Economy Pay Off? Evaluating Global Forecasts from a Bayesian GVAR *
}

\author{
Jonas Dovern $^{1}$, Martin Feldkircher ${ }^{2}$, and Florian Huber ${ }^{2}$ \\ ${ }^{1}$ Alfred-Weber-Institute for Economics, Heidelberg University \\ ${ }^{2}$ Oesterreichische Nationalbank (OeNB)
}

\begin{abstract}
We analyze how modeling international dependencies improves forecasts for the global economy based on a Bayesian GVAR with SSVS prior and stochastic volatility. To analyze the source of performance gains, we decompose the predictive joint density into its marginals and a copula term capturing the dependence structure across countries. The GVAR outperforms forecasts based on country-specific models. This performance is solely driven by superior predictions for the dependence structure across countries, whereas the GVAR does not yield better predictive marginal densities. The relative performance gains of the GVAR model are particularly pronounced during volatile periods and for emerging economies.
\end{abstract}

JEL classification: C53, E37, F47

Keywords: GVAR, global economy, forecast evaluation, log score, copula

\footnotetext{
${ }^{*}$ Corresponding author: Florian Huber, Oesterreichische Nationalbank (OeNB), Phone: $+43-$ 1-404 20-5208. E-mail: florian.huber@oenb.at. We would like to thank Hans Manner and all participants of the AWI seminar as well as the OeNB seminar for helpful comments on earlier drafts of this paper. The opinions expressed in this paper are those of the authors and do not necessarily reflect the official viewpoint of the OeNB or of the Eurosystem.
} 


\section{Non-Technical Summary}

The rise in international trade and cross-border financial flows over the last decades implies that countries are more than ever exposed to economic shocks from abroad, a fact that was recently demonstrated by the global financial crisis. Macroeconomic tools that treat countries as isolated from the rest of the world may, hence, miss important information for forecasting and counterfactual analysis. In particular, forecasters dealing with global economic policy issues or risk management need to have a good understanding of how to optimally model national economies that are strongly integrated with the world economy. On top of that, global economic projections must be coherent across countries. Against this backdrop, global vector autoregressive (GVAR) models constitute a useful econometric framework that accommodates spillovers from the global economy in a tractable manner. GVAR specifications consist of single country models that are stacked to yield a comprehensive representation of the world economy and have been recently proposed as a forecasting tool to yield coherent forecasts across countries.

This paper extends existing work along two dimensions: First, we focus on density as opposed to point forecasts in a global setting. Density forecasts constitute an estimate of the probability distribution of the possible future values of a variable of interest. They thus provides a complete description of the uncertainty associated with a prediction and stands in contrast to a point forecast which by itself contains no description of the associated uncertainty. Especially in times of heightened uncertainty, such as during the period of the recent global financial crisis, point forecasts can be highly misleading for policymakers. Second, we seek to forecast and assess forecasts for a range of variables jointly. These comprise international data on real GDP, the change of the consumer price levels, real equity prices, the real exchange rate, and short- and long-term interest rates. In total, our model describes the world economy based on more than 200 variables.

Our results suggest that there are clear gains from using GVAR models when the aim is to coherently forecast the economies of a range of countries. This result holds true for the entire evaluation period of our forecasting sample but especially so during the period of the global financial crisis 2008/09. By using a decomposition of the joint predictive density, we show that the performance gains of the GVAR are exclusively driven by better predictions of the cross-country interlinkages. We proceed by separately estimating two regional GVAR models for advanced and emerging economies. A forecast analysis based on these models indicates no deterioration of forecasts for advanced economies when emerging economies are excluded in the regional GVAR. By contrast, shutting down spillover effects from advanced to emerging economies significantly deteriorates the quality of forecasts for emerging economies. This implies that while advanced economies could be modeled more parsimoniously taking into account only within-region spillover effects, forecasts for emerging economies can be significantly improved by considering information from advanced economies. However, for both regions the truly global GVAR framework featuring all economies in the sample excels in forecasting during the global financial crisis. 


\section{Introduction}

Forecasters dealing with global economic policy issues or risk management need to have a good understanding of how to optimally model national economies that are strongly integrated with the world economy. Global economic projections must, above all, be coherent across countries. ${ }^{1}$

Against this backdrop, global vector autoregressive (GVAR) models (Pesaran et al., 2004) have been proposed as a forecasting tool (Pesaran et al., 2009) because such models cover all major economies of the world and their interactions. While forecast coherence is potentially the major advantage of GVAR models as a forecasting tool, past assessments of the forecast performance of GVAR models have been conducted variable by variable, i. e., from a univariate perspective. However, for forecasters seeking to forecast a range of variables (e. g., GDP growth in all countries) or to review the joint predictive density of the entire system, such univariate evaluation approaches clearly miss important aspects. ${ }^{2}$ The idea is very intuitive: Two vector forecasts with the same accuracy in terms of marginal predictive densities could perform very differently in terms of the copula that links the marginal distributions and captures the dependencies between the vector elements. In fact, even a model that performs significantly worse compared to a benchmark model in terms of predicting the marginal densities could yield superior joint predictive densities.

We add to the literature by assessing the forecast performance of a GVAR model from a multivariate perspective: we analyze whether the rich model structure of GVAR models pays off by yielding superior predictive joint densities relative to

\footnotetext{
${ }^{1}$ Think, for instance, of the business-cycle forecasts published by the International Monetary Fund (IMF) for all member states in its World Economic Outlook (WEO). The IMF has to make sure that the individual country-specific forecasts are coherent in that they reflect the same view about the outlook of the world economy and historical experience with co-movement of business cycles across countries. A recent investigation reports that top-down elements are important in the production process of the WEO (IEO, 2014).

${ }^{2}$ This point was raised already in a comment by Swanson (2009) in response to the seminal paper by Pesaran et al. (2009).
} 
a benchmark that consists of country-specific forecast models. Our paper makes several contributions. First, it is the first analysis of GVAR forecast performance in terms of the overall joint predictive density of all model variables. Second, we suggest to decompose the joint predictive density into the marginal densities and a copula term to analyze the source of performance gains in more detail. Finally, we enhance the Bayesian estimation of GVAR models. We modify the Bayesian GVAR model with stochastic volatility as outlined by Huber (2014) and introduce a variant of the stochastic search variable selection (SSVS) prior. Using a restricted stochastic volatility model in the spirit of Carriero et al. (2012) and a conjugate version of the SSVS prior leads to significant computational gains that are essential when estimating large-scale models such as the GVAR.

Our paper is linked to a number of companion papers that develop a Bayesian framework for GVAR models and analyze the forecast performance of such Bayesian GVAR models. Crespo Cuaresma et al. (2014a) put forward a Bayesian version of the GVAR model and analyze how different prior setups perform in terms of yielding accurate density forecasts. They find that the SSVS prior, on which we concentrade in this paper, exhibit the best forecasting ability among a wide range of priors. Huber (2014) shows how a Bayesian GVAR model can be augmented to account for stochastic volatility. Finally, Dovern and Huber (2015) show, in a complementary paper, that the GVAR model used in the paper at hand yields better turning point prediction than country-specific time-series models.

The main results of this paper can be summarized as follows: First, the GVAR model outperforms, on average, the country-specific Bayesian VAR models with stochastic volatility, which are used as a benchmark, in terms of the quality of the joint predictive density. This holds true also for all types of variables (financial and real) separately. Second, these performance gains are driven by better predictions for the dependence structure across variables and countries rather than by improved predictive marginal densities. Third, the forecast performance of both the GVAR 
and the country-specific benchmark models is strongly time-varying, and forecasts deteriorate during the global recession. However, the loss in forecast accuracy during turbulent times is much smaller for the GVAR model than for the benchmark models. That is, incorporating international linkages among countries is essential for forecasting and in particular so during crisis times. Last, and taking a regional angle, the gains of using a world-wide model seem particularly pronounced for emerging economies. More specifically, while taking cross-country linkages between advanced economies into account seems sufficient to generate accurate forecasts for these countries, forecasts for emerging economies tend to improve when based on a truly global sample. Taken at face value this means that modeling spillovers from advanced to emerging economies tends to improve forecasts for these countries, whereas the opposite is not true.

The remainder of this paper is structured as follows. Section 2 summarizes the

relevant literature. Section 3 presents the model framework that we use. It explains the structures of the GVAR model as well as our benchmark model and describes our estimation strategy. Section 4 documents the data set that we use and specifies the choices that we make with respect to the priors of the Bayesian GVAR model. Section 5 describes the design of our out-of-sample forecast analysis and documents the evaluation criteria that we use. Section 6 contains the empirical results. It documents the baseline results and shows how the performance of GVAR forecasts varies over time and across different country groups. Finally, Section 7 concludes the paper.

\section{Related Literature}

Our paper builds on the growing literature on GVAR models. This type of model, which was proposed by Pesaran et al. (2004) and further developed by Dées et al. (2007a) and Dées et al. (2007b), is designed to model dependencies across a wide range of macroeconomic variables from a large number of countries. GVAR models 
capture the dynamics of a large part of the world economy by linking countryspecific vector autoregressive (VAR) models to each other. GVAR models were first developed as a tool for financial stress-testing following the Asian crisis in the late 1990s. Since then, they have been heavily used to analyze the dynamic effects of a wide range of country-specific or global shocks. ${ }^{3}$

More recently, GVAR models have been proposed as a tool for forecasting global economic activity (Pesaran et al., 2009). Most studies attest GVAR models a forecast performance that is about as good or slightly better, on average, as that of simpler benchmark models. Pesaran et al. (2009) find superior performance of GVAR forecasts (relative to univariate benchmark models) for output growth and inflation when they obtain GVAR forecasts by averaging over different model specifications. ${ }^{4}$ In contrast, the performance is more mediocre for forecasting financial variables such as interest rates or equity prices. Greenwood-Nimmo et al. (2012) use a GVAR model with country-specific intercept shifts to produce probabilistic forecasts for a number of variables in major economies. They show that forecasts based on the GVAR model outperform univariate benchmark models especially over long forecast horizons. Crespo Cuaresma et al. (2014a) estimate a Bayesian GVAR model and show that forecasts based on this model outperform forecasts from several univariate benchmark models for virtually all variables and different forecast horizons. Two other recent contributions have looked at the forecast performance of GVAR models for small open economies: Assenmacher (2013) shows that a small GVAR model for the Swiss economy delivers forecasts that are comparable in accuracy with widely used benchmark forecasts. de Waal et al. (2013) show that a richer GVAR

\footnotetext{
${ }^{3}$ GVAR models have, for instance, been used to analyze the international transmission of oil price shocks (Cashin et al., 2014), house price shocks (Cesa-Bianchi, 2013), credit supply shocks (Eickmeier and Ng, 2015), cost-push shocks (Galesi and Lombardi, 2013), financial stress shocks (Dovern and van Roye, 2014), monetary policy shocks (Feldkircher and Huber, 2015), liquidity shocks during the Great Recession of 2007-2009 (Chudik and Fratzscher, 2011), and for stresstesting of the financial sector (Castrén et al., 2010). For a more complete overview, see Chudik and Pesaran (2014).

${ }^{4}$ It remains unclear from their paper how much the performance of the univariate models could be improved by averaging over different models/specifications. The study by Pesaran et al. (2009) has been updated with similar findings by Smith (2013).
} 
model delivers better forecasts for the South African economy than a small version including only the three main trading partners. They show, however, that Bayesian country-specific VAR models and univariate autoregressive models tend to beat the GVAR models in terms of forecast accuracy.

Our work relates also to the literature on econometric models that account for stochastic volatility. The recent synchronous increase in the volatility of many macroeconomic variables suggests that traditional linear models fail to properly capture salient features of the data. Clark (2011) uses a standard VAR augmented by stochastic volatility (SV) to produce predictive densities for a set of macroeconomic aggregates. He concludes that allowing for stochastic volatility generally improves the accuracy of density forecasts. Recently, Carriero et al. (2012) proposed a Bayesian VAR with stochastic volatility, which exploits the fact that most macroeconomic variables obey the same pattern of realized volatility. They conclude that imposing a factor structure on the latent log-volatilities helps to improve the accuracy of the density forecasts at little additional costs in terms of computational demands. Huber (2014) proposes a GVAR model with a factor SV structure. He reports that allowing each country's volatility to be driven by a country-specific latent factor improves forecasts of GDP and short-term interest rates, while leading to no improvements for forecasts of inflation, real exchange rates and long-term interest rates.

The third related strand of literature is concerned with multivariate evaluation of vector forecasts. Since we are going to evaluate density forecasts, the methods that we use are most closely linked with the literature on multivariate evaluation of such forecasts which was initiated among others by Diebold et al. (1999) and which is surveyed in Gneiting (2008). Our study is complementary to a number of recent papers that address the issue of evaluating vector-valued point forecasts from a multivariate perspective (see, e.g., Eisenbeis et al., 2002; Bauer et al., 2003; Sinclair and Stekler, 2013; Müller-Dröge et al., 2014). 


\section{Model Framework}

GVAR models (Pesaran et al., 2004) are designed to capture the dynamics of a large part of the world economy by linking country-specific vector autoregressive models to each other using trade weights. Though GVAR models are linear, they allow for a range of different interdependencies between variables and countries, such as longrun relationships consistent with theory, short-run spillover effects or cross-sectional dependence in the error structure. Thus, they offer a fair degree of flexibility in modeling the business-cycle dynamics of the world economy in a coherent fashion. In the following sections, we briefly sketch the assumptions that we make about the specification of the GVAR model, and we explain what priors we use for the Bayesian estimation of the model and how we generate density forecasts based on the estimated GVAR model.

\subsection{Global Vector Autoregressive Models}

Basically, a GVAR model consists of a number of country-specific models that are combined to form the global model. In a first step, the country-specific models can be estimated individually under certain restrictions. In a second step, the GVAR model is "solved" by combining the individual models. Consider a sample of $N+1$ different countries. Let $x_{i, t}$ be the $k_{i} \times 1$ vector of domestic random variables for country $i=0, \ldots, N$ and time $t=1, \ldots, T$. For each country, we consider a VAR model which is augmented with a set of (weakly exogenous) foreign variables (VARX*). To enhance readability of the notation, we restrict all formulas to a $\operatorname{VARX}^{*}(1,1)$ specification although we allow for three lags in our empirical application:

$$
x_{i, t}=a_{i 0}+a_{i 1} t+\Phi_{i 1} x_{i, t-1}+\Lambda_{i 0} x_{i, t}^{*}+\Lambda_{i 1} x_{i, t-1}^{*}+\varepsilon_{i, t} .
$$

Here, $a_{i 0}, a_{i 1}, \Phi_{i 1}, \Lambda_{i 0}$ and $\Lambda_{i 1}$ are properly sized coefficient matrices measuring the impact of deterministic components, lagged domestic variables and foreign variables. 
The foreign variables are calculated as a weighted average of the domestic variables of all other countries based on trade weights, $x_{i, t}^{*}=\sum_{j=0}^{N} w_{i j} x_{j, t}$, under the restriction that $w_{i i}=0$ and $\sum_{j=0}^{N} w_{i j}=1$. The assumption that $x_{i, t}^{*}$ is weakly exogenous at the individual country level reflects the belief that most countries are small relative to the world economy.

Most existing papers on GVAR models make the assumption of a fixed covariance matrix for $\varepsilon_{i, t}$. We are skeptical about this approach, tough. Especially for fastmoving financial variables, this assumption proves inadequate in the presence of sudden shifts in the level of volatility and volatility-clustering. Therefore, we assume that $\varepsilon_{i, t} \sim N\left(0, \Sigma_{i, t}\right)$. Following Carriero et al. (2012) and Huber (2014), we use the following stochastic volatility specification

$$
\begin{aligned}
\Sigma_{i, t} & =\exp \left(h_{i, t}\right) \times \Sigma_{i} \\
h_{i, t} & =\kappa_{i}+\rho_{i}\left(h_{i, t-1}-\kappa_{i}\right)+\eta_{i} u_{i, t} \\
u_{i, t} & \sim N(0,1),
\end{aligned}
$$

where $h_{i, t}$ denotes a country-specific log-volatility process, with $\kappa_{i}$ being its unconditional mean and $\rho_{i}$ an autoregressive parameter. ${ }^{5}$ Finally, $\eta_{i}$ denotes the variance of the log-volatility process. To identify the model it is sufficient to set $h_{i, 0}=0$. Note that we assume that the variance of the entire VARX* is driven by a single latent process. This is justified because most macro variables exhibit similar volatility dynamics and especially when it comes to predicting financial crises the correlation between variables tends to increase dramatically. ${ }^{6}$ Huber (2014) showed empirically that (for a smaller information set) the differences between a full stochastic volatility

\footnotetext{
${ }^{5}$ We depart from the macroeconomic literature by assuming that the log-volatility follows an autoregressive process of order one rather than a random walk. This choice, motivated in Eisenstat and Strachan (2014) implies that in the limit, the level of the volatility is bounded in probabilistic terms.

${ }^{6}$ Even though the number of additional parameters to be estimated would not increase dramatically by assuming that $k_{i} \log$-processes govern the behavior of $\Sigma_{i, t}$, we would lose several convenient features of the estimation algorithm, which would induce significant computational costs.
} 
specification and the simplified variant proposed above tend to be rather small for most countries considered.

Pesaran et al. (2004) show how the $N+1$ country models can be combined to yield a global VAR representation. Defining a $\left(k_{i}+k_{i}^{*}\right) \times 1$ vector $z_{i, t}=\left(x_{i, t}^{\prime}, x_{i, t}^{*}{ }^{\prime}{ }^{\prime}\right.$, collecting all contemporaneous terms on the left-hand side and ignoring deterministic terms for notational simplicity, we can rewrite equation (3.1) as

$$
A_{i} z_{i, t}=B_{i} z_{i, t-1}+\varepsilon_{i, t}
$$

with $A_{i}=\left(I_{k_{i}},-\Lambda_{i, 0}\right)$ and $B_{i}=\left(\Phi_{i 1}, \Lambda_{i 1}\right)$ denoting $k_{i} \times\left(k_{i}+k_{i}^{*}\right)$-dimensional matrices, respectively. We collect all endogenous variables in a $k \times 1$ global vector $x_{t}=\left(x_{0, t}^{\prime}, x_{1, t}^{\prime}, \ldots, x_{N, t}^{\prime}\right)^{\prime}$, where $k=\sum_{i=0}^{N} k_{i}$ is the total number of endogenous variables in the GVAR. By defining a suitable $\left(k_{i}+k_{i}^{*}\right) \times k$ linking matrix $W_{i}$, it is possible to rewrite $z_{i, t}$ exclusively in terms of $x_{t}$ and $W_{i}$. More specifically, the linking matrix is set such that the following equality holds

$$
z_{i t}=W_{i} x_{t}
$$

Inserting equation (3.6) into equation (3.5) and stacking the models for all countries yields

$$
G x_{t}=H x_{t-1}+\varepsilon_{t},
$$

where $G=\left(\left(A_{0} W_{0}\right)^{\prime}, \ldots,\left(A_{N} W_{N}\right)^{\prime}\right)^{\prime}, H=\left(\left(B_{0} W_{0}\right)^{\prime}, \ldots,\left(B_{N} W_{N}\right)^{\prime}\right)^{\prime}$, and $\varepsilon_{t}=$ $\left(\varepsilon_{0, t}^{\prime}, \ldots, \varepsilon_{N, t}^{\prime}\right)^{\prime}$. Multiplying from the left by $G^{-1}$ yields the reduced-form GVAR representation:

$$
x_{t}=F x_{t-1}+e_{t},
$$

where $F=G^{-1} H$ and $e_{t}=G^{-1} \varepsilon_{t}$. Equation (3.8) resembles a standard first-order reduced form VAR. The structure of the VARX* model induces restrictions on the parameter matrix $F$. In addition to the restrictions imposed on $F$, the structure of 
the model has important implications for the specific form of the variance-covariance matrix of $e_{t}, \Sigma_{e, t}$. In the present application, $\Sigma_{e, t}$ is a positive definite matrix, given by

$$
\Sigma_{e, t}=G^{-1} \Sigma_{\varepsilon, t} G^{-1^{\prime}}
$$

$\Sigma_{\varepsilon, t}$ is a block-diagonal matrix which consists of the country-specific variance-covariance matrices $\Sigma_{i, t}$. The block-diagonality of $\Sigma_{\varepsilon, t}$ is predicated by the fact that the inclusion of the weakly exogenous variables accounts for cross-country correlation and renders the estimation problem of the $N+1$ submodels embarrassingly parallel, providing significant computational advantages.

\subsection{Selection of Priors and Estimation}

We consider a Bayesian version of the GVAR model as introduced by Crespo Cuaresma et al. (2014a) and rely on the stochastic search variable selection (SSVS) prior on the coefficients, which Crespo Cuaresma et al. (2014a) demonstrated to yield excellent forecasts. Since we are going to use a slightly more complex framework allowing for SV, we modify the prior setup from Crespo Cuaresma et al. (2014a) and propose a (conditionally) conjugate version of the SSVS prior. This allows us to reduce the computational burden significantly. Additionally, as noted above, the factor structure of the log-volatilities permits us to exploit a convenient Kronecker structure of the likelihood function.

For prior implementation it proves convenient to rewrite the VARX* in equation (3.1) in the following way

$$
x_{i, t}=\Gamma_{i} Z_{i t}+\varepsilon_{i t},
$$

where $Z_{i, t}=\left(1, t, x_{i, t-1}^{\prime}, x_{i, t}^{*}, x_{i, t-1}^{*}\right)^{\prime}$ is a $K_{i}$-dimensional data vector, where $K_{i}=$ $2+k_{i}+2 k_{i}^{*}$. The $k_{i} \times K_{i}$ matrix of stacked coefficients is denoted by $\Gamma_{i}=$ $\left(a_{i 0}, a_{i 1}, \Phi_{i 1}, \Lambda_{i 0}, \Lambda_{i 1}\right)$. Furthermore, let us denote the vectorized coefficient matrix as $\Psi_{i}=\operatorname{vec}\left(\Gamma_{i}\right)$. Our stochastic volatility setup can be implemented in a straight- 
forward fashion by dividing $x_{i, t}$ and $Z_{i, t}$ by $\exp \left(h_{i t} / 2\right)$, where the normalized data matrices are denoted by $\tilde{x}_{i, t}$ and $\tilde{Z}_{i, t}$. Finally, we denote full data matrices by $\tilde{Z}_{i}=\left(\tilde{Z}_{i, 0}^{\prime}, \tilde{Z}_{i, 1}^{\prime}, \ldots, \tilde{Z}_{i, T}^{\prime}\right)^{\prime}$ and $\tilde{x}_{i}=\left(\tilde{x}_{i, 0}^{\prime}, \tilde{x}_{i, 1}^{\prime}, \ldots, \tilde{x}_{i, T}^{\prime}\right)^{\prime}$.

As advocated in Carriero et al. (2012), we use the following conjugate prior setup on $\Psi_{i}$ and $\Sigma_{i}^{-1}$

$$
\begin{aligned}
\Psi_{i} \mid \Sigma_{i}^{-1}, \psi_{i} & \sim \mathcal{N}\left(\underline{\mu}_{\Psi_{i}}, \Sigma_{i} \otimes \underline{V}_{\Psi_{i}}\right), \\
\Sigma_{i}^{-1} & \sim \mathcal{W}\left(\underline{v}_{i}, \underline{S}_{i}\right),
\end{aligned}
$$

where $\psi_{i}=\left(\psi_{i 1}, \ldots, \psi_{i K_{i}}\right)^{\prime}$ denotes a vector of binary random variables. This implies that conditional on $\psi_{i}$, the prior on the dynamic coefficients is a standard conjugate prior with mean $\underline{\mu}_{\Psi_{i}}$ and variance $\Sigma_{i} \otimes \underline{V}_{\Psi_{i}}$. Knowledge of $\psi_{i}$ fully specifies $\underline{V}_{\Psi_{i}}$. More specifically, $\underline{V}_{\Psi_{i}}$ is a diagonal matrix where the $(j, j)^{t h}$ element is given by $v_{j}$, with

$$
v_{j}= \begin{cases}\tau_{0 j}^{2} & \text { if } \psi_{i j}=0 \\ \tau_{1 j}^{2} & \text { if } \psi_{i j}=1 .\end{cases}
$$

$\tau_{0 j}$ and $\tau_{1 j}$ are prior-variances set such that $\tau_{1 j} \gg \tau_{0 j}$. By setting $\underline{\mu}_{\Psi_{i}}$ equal to zero, equation (3.13) implies that we impose a mixture prior on the different variable types in (3.1) similar to the prior discussed in Koop (2013). To see this, let us define the element corresponding to the $l$ th equation and the $j$ th variable as $\left[\Gamma_{i}\right]_{l j}$. Under the assumption that the prior mean is set equal to zero, we impose the following mixture prior

$$
\left[\Gamma_{i}\right]_{l j} \mid \psi_{i j} \sim\left(1-\psi_{i j}\right) \mathcal{N}\left(0, \sigma_{i l l} \tau_{0, i j}^{2}\right)+\psi_{i j} \mathcal{N}\left(0, \sigma_{i l l} \tau_{1, i j}^{2}\right)
$$

for $l=1, \ldots, k_{i}, j=1, \ldots, K_{i}$ and $\sigma_{i l l}=\left[\Sigma_{i}\right]_{l l}$. Thus $\psi_{i j}$ controls which of the two Normal distributions applies for the $j$ th regressor. Since the Normal distributions differ only by their variances, and the variances are set such that $\tau_{1 j} \gg \tau_{0 j}$, we 
either impose a dogmatic or a loose prior on $\left[\Gamma_{i}\right]_{l j} \cdot{ }^{7}$ In contrast to the traditional implementation of the SSVS prior in the spirit of George et al. (2008), the conjugate SSVS specification either includes or excludes a given explanatory variable in all equations of a particular country model. The SSVS prior thus allows us to account for model uncertainty at the individual country level. This is important since our sample spans a broad set of different economies, each being fundamentally different from each other. Thus assuming too much homogeneity in terms of model specification could distort inference and lead to a poor out-of-sample forecasting performance. In addition, uncertainty with respect to the appropriate lag-length is also tackled through the SSVS prior.

For $\Sigma_{i}^{-1}$ we impose a standard Wishart prior with scaling matrix $\underline{S}_{i}$ and degrees of freedom $\underline{v}_{i}$. Note that we assume prior dependence between $\Sigma_{i}^{-1}$ and $\Psi_{i}$.

Finally, we also have to impose prior distributions on the parameters of the logvolatility equation. Following Frühwirth-Schnatter and Wagner (2010) and Kastner and Frühwirth-Schnatter (2014), we impose the following set of priors:

$$
\begin{aligned}
\kappa_{i} & \sim \mathcal{N}\left(\underline{\mu}_{\kappa_{i}}, \underline{V}_{\kappa_{i}}\right), \\
\frac{\rho_{i}+1}{2} & \sim \mathcal{B}\left(a_{1}, b_{1}\right), \\
\eta_{i} & \sim \mathcal{G}\left(\frac{1}{2}, \frac{1}{2} R_{\eta_{i}}\right) .
\end{aligned}
$$

We use a Normal prior on the level of the log-volatility process $\kappa_{i}$, a Beta prior on the autoregressive parameter $\rho_{i}$, and a non-conjugate Gamma prior on the variance of the log-volatility specification with a scalar hyperparameter $R_{\eta_{i}}$.

Due to the conjugacy of the prior setup, "dummy observations" can be used to implement the prior (see Bańbura et al., 2010; Koop, 2013). This implies that the conjugate SSVS prior can be implemented using the following artificial observations

\footnotetext{
${ }^{7}$ Thus, if $\psi_{i j}$ equals zero, the prior variance is set to a very small value, indicating that the posterior distribution of the associated coefficient will shrink towards zero. Otherwise, the coefficient could be anything on the real line.
} 


$$
\underline{x}_{i}=\left(\begin{array}{c}
\underline{V}_{\Psi_{i}}^{-\frac{1}{2}} \underline{A} \\
\operatorname{diag}\left(s_{1}, \ldots, s_{k_{i}}\right)
\end{array}\right), \quad \underline{Z}_{i}=\left(\begin{array}{c}
\underline{V}_{\Psi_{i}}^{-\frac{1}{2}} \\
0_{k_{i} \times K_{i}}
\end{array}\right)
$$

where $\underline{V}_{\Psi_{i}}^{-\frac{1}{2}}$ is defined by $\underline{V}_{\Psi_{i}}=\underline{V}_{\Psi_{i}}^{\frac{1}{2}} \underline{V}_{\Psi_{i}}^{\frac{1}{2}}$ and $\underline{A}$ equals the zero matrix. ${ }^{8}$ Following Doan et al. (1984), $s_{1}, \ldots, s_{k_{i}}$ are the residual standard deviations from a set of $k_{i}$ univariate autoregressions of order four for the elements of $x_{i, t}$. Finally, $0_{k_{i} \times K_{i}}$ denotes a $k_{i} \times K_{i}$ matrix of zeros.

Combining the "dummy observations" with the real data, we obtain the following quantities:

$$
\bar{x}_{i}=\left(\begin{array}{c}
\tilde{x}_{i} \\
\underline{x}_{i}
\end{array}\right), \quad \bar{Z}_{i}=\left(\begin{array}{c}
\tilde{Z}_{i} \\
\underline{Z}_{i}
\end{array}\right) .
$$

It can be shown, that this prior setup gives rise to the following posterior distributions:

$$
\begin{aligned}
\Psi_{i} \mid \Sigma_{i}^{-1}, \psi_{i}, h_{i}, \mathcal{D}_{i T} & \sim \mathcal{N}\left(\bar{\mu}_{\Psi_{i}}, \bar{V}_{\Psi_{i}}\right) \\
\Sigma_{i}^{-1} \mid \Psi_{i}, \psi_{i}, h_{i}, \mathcal{D}_{i T} & \sim \mathcal{W}\left(\bar{v}_{i}, \bar{S}_{i}\right)
\end{aligned}
$$

where $h_{i}=\left(h_{i, 0}, \ldots, h_{i, T}\right)$ denotes the full history of log-volatilities and $\mathcal{D}_{i T}$ denotes the data specific to country $i$ up to time $T$. The posterior mean and variance for $\Psi_{i}$ are given by $\bar{V}_{\Psi_{i}}=\left(\bar{Z}_{i}^{\prime} \bar{Z}_{i}\right)^{-1}$ and $\bar{\mu}_{\Psi_{i}}=\bar{V}_{\Psi_{i}} \bar{Z}_{i}^{\prime} \bar{x}_{i}$, the posterior scaling matrix for $\Sigma_{i}^{-1}$ is given by $\bar{S}_{i}=\left(\bar{x}_{i}-\bar{Z}_{i} \bar{\mu}_{\Psi_{i}}\right)^{\prime}\left(\bar{x}_{i}-\bar{Z}_{i} \bar{\mu}_{\Psi_{i}}\right)$, and the posterior degrees of freedom are simply $\bar{v}_{i}=T+\underline{v}_{i}$.

Due to conjugacy, $\Psi_{i}$ and $\Sigma_{i}^{-1}$ can be simulated using a simple Gibbs sampler by drawing sequentially from the appropriate Normal and Wishart distributions. Unfortunately, the conditional posterior distributions of the remaining parameters are not available in closed form. Hence, for these parameters we have to use other posterior simulation strategies. For $\psi_{i}$, we depart from Brown et al. (1998b) and

\footnotetext{
${ }^{8}$ The first $k_{i}$ rows and columns of $\underline{A}$ correspond to the prior means on the first lag of the endogenous variables, which is set equal to zero in the present application.
} 
Koop (2013) and use a Markov Chain Monte Carlo Model Composition step in the spirit of Brown et al. (1998a). In short, this implies starting with the full model (i. e., all elements of $\psi_{i}$ are set equal to one) and then using a simple birthdeath sampler to explore the posterior distribution (Madigan and York, 1995). The history of log-volatilities and the corresponding parameters are sampled using an ancillarity sufficiency interweaving strategy proposed in Kastner and FrühwirthSchnatter (2014).

This algorithm allows us to draw from the country-specific joint posterior distributions. However, for the subsequent forecasting exercise, we need estimates for the global posterior distribution, i. e., the posterior quantities for the parameters of equation (3.8), $p\left(F, \Sigma_{e, t}, h \mid \mathcal{D}_{T}\right)$, with $\mathcal{D}_{T}$ denoting the full data set available for all countries up to time $T$ and $h$ is the $(N+1) \times T$ matrix collecting all log-volatilities. Drawing from the individual country posterior distributions and using the algebra outlined above allows us to obtain valid draws from the posterior distribution of $F$ and $\Sigma_{e, t}$. Knowing $p\left(F, \Sigma_{e, t}, h \mid \mathcal{D}_{T}\right)$, we can use Monte Carlo integration to obtain any quantity of interest like predictive densities or impulse response functions.

\subsection{Benchmark Model}

With a view to assessing the potential superiority of GVAR models over countryspecific models, we select a set of country-specific Bayesian vector autoregression (BVAR) models with stochastic volatility as a benchmark. ${ }^{9}$ We obtain this benchmark by 'shutting down' the interaction between variables from different countries in our baseline GVAR.

More formally, we restrict the impact of the foreign variables to zero in all equations of the model by setting $\Lambda_{i 0}$ and $\Lambda_{i 1}$ equal to zero matrices in equation (3.1). It follows that $G$ has a block-diagonal structure such that also the covariance matrix

\footnotetext{
${ }^{9}$ We believe that this is a more natural benchmark than traditional univariate models (as, e. g., in Pesaran et al., 2009), which might be overly restrictive for macroeconomic variables such as growth rates or inflation.
} 
$\Sigma_{e, t}$, given in equation (3.9) remains block-diagonal. In other words: the benchmark model neither allows for contemporaneous nor lagged spillover effects between any pair of two countries.

It is worth emphasizing that since the benchmark model is nested within the GVAR, prior choices are only of minor importance for the empirical application that follows. ${ }^{10}$ A comparison based on "classical" estimated GVAR models is difficult since our model accounts for heteroscedasticity in a flexible manner. ${ }^{11}$

\section{Data \& Prior Implementation}

\subsection{Data Overview}

We extend the data set used in previous studies (Dées et al., 2007a;b) with respect to country coverage and time span. More specifically, we use quarterly data for 36 countries (see Table 1) spanning the period from 1979q2 to $2013 \mathrm{q} 4$.

[Table 1 about here.]

The domestic variables that are covered in our analysis are real activity (GDP), the change of the consumer price level, real equity prices, the real exchange rate, and short- and long-term interest rates. Thus, our data set features the same variables as Dées et al. (2007a,b) and Pesaran et al. (2009). We follow the bulk of the literature by including oil prices as a global control variable and by using bilateral trade flows as the measure of economic proximity between countries. That is, we construct the weakly exogenous foreign variables based on the average bilateral annual trade flows in the period from 1980 to 2003, which denotes the end of our initial estimation sample. $^{12}$ Following Crespo Cuaresma et al. (2014a) and Feldkircher and Huber

\footnotetext{
${ }^{10}$ This holds true as long as we assume the same set of priors for both specifications.

${ }^{11}$ For a comparison between Bayesian GVARs and classical GVARs see Crespo Cuaresma et al. (2014b).

${ }^{12}$ Note that recent contributions (Dovern and van Roye, 2014; Eickmeier and Ng, 2015) suggest using financial data to compute foreign variables related to the financial side of the economy (e.g., interest rates or credit volumes). Since our data sample starts in the early 1980s, reliable data on financial flows - such as portfolio flows or foreign direct investment - are not available. See the
} 
(2015), we calculate foreign counterparts for all variables including the bilateral real exchange rate vis-á-vis the U.S. dollar. ${ }^{13}$

The U.S. model deviates from the other country models in that the oil price is determined within that country-model. The dominant role of the U.S. economy for global financial markets is often accounted for by including only a limited set of weakly exogenous variables. It is not necessary to impose this ad-hoc restriction in our Bayesian approach since it entails variable selection at the country model level.

Finally we correct for outliers in countries that witnessed crisis-induced, extraordinarily strong movements in some of the variables contained in our data. We opted to smooth the relevant time series in these cases. ${ }^{14}$ In particular, this applies to the short-term interest rate in Argentina during the periods 1983q4, 1984q3 to 1985q2, 1989q2, and 1990q1. The data are described in more detail in Table 2. ${ }^{15}$

[Table 2 about here.]

\subsection{Prior Implementation}

To implement the prior setup discussed above, we have to specify suitable hyperparameters for all priors. For the prior on $\Psi_{i}$, we scale the prior variances using the so-called "semi-automatic" approach put forward in George et al. (2008). This implies that the prior variances are scaled by the respective least squares variance of the parameter in question. However, due to the fact that we only have to specify $K_{i}$ variance parameters, we follow Koop (2013) and use the maximum of the variance corresponding to each variable type across all equations.

appendix of Feldkircher and Huber (2015) for a sensitivity analysis with respect to the choice of weights.

${ }^{13}$ Carriero et al. (2009) show that controlling for co-movements of currencies is important to improve macroeconomic forecasts.

${ }^{14}$ Alternatively one could introduce a set of dummy variables for the observations in question as in Crespo Cuaresma et al. (2014a) or Feldkircher and Huber (2015). While this might improve the behavior of the country-models' residuals, it still poses the risk that outlier effects could be carried over to other country models via the trade-weighted foreign variables.

${ }^{15}$ With the exception of long-term interest rates, the cross-country coverage of all variables is above $90 \%$. Long-term interest rates are hardly available for emerging markets that do not feature well developed capital markets. 
The prior on the precision matrix, $\Sigma_{i}^{-1}$, is rendered fairly uninformative by setting $\underline{S}_{i}=I_{k_{i}}$ and $\underline{v}_{i}=k_{i}$. Robustness checks lead to the conclusion that this specific prior choice proves to be non-influential for the qualitative ordering of the models discussed.

For the autoregressive parameter in the log-volatility equation $\rho_{i}$, we set $a_{1}=25$ and $b_{1}=1.5$, resulting in a prior mean of 0.89 and standard deviation of 0.08 . This puts most prior mass on positive values of $\rho_{i}$. This prior choice implements the view that the log-volatility follows a fairly persistent autoregressive process rather than a random walk. Due to the fact that our time series are rather short for a model that deals with stochastic volatility, the choice of the hyperparameter is rather crucial in empirical applications. However, robustness checks indicate that the qualitative ordering of the models remains unaffected by changes in the quantitative results. The prior on the level of the log-volatility is set to be uninformative given the scale of data. This implies that we set $\underline{\mu}_{\kappa_{i}}=0$ and $\underline{V}_{\kappa_{i}}=10$. Finally, for the Gamma prior of the variance of the log-volatility equation, we set $R_{\eta_{i}}=1$. This choice is of minor influence in our application.

\section{Design of Out-of-Sample Forecast Analysis}

Given the posterior distribution of the model parameters, simulating predictive densities for different forecast horizons is straightforward. More formally, the $r$-stepsahead predictive density for the model in (3.8) in period $\tau$ is given by

$$
p\left(x_{\tau+r} \mid \mathcal{D}_{\tau}\right)=\int_{\Xi} p\left(x_{\tau+r} \mid \Xi, \mathcal{D}_{\tau}\right) p\left(\Xi \mid \mathcal{D}_{\tau}\right) d \Xi
$$

where $\Xi=\left\{F, \Sigma_{e, t}, h\right\}$ denotes all estimated parameters of the GVAR model. As mentioned above, estimates for (5.1) are readily available using a numerical approximation. 
We propose the following recursive forecasting exercise. Beginning in $\tau=t_{0}$, we re-estimate the GVAR and simulate the predictive density $p\left(x_{\tau+r} \mid \mathcal{D}_{\tau}\right)$ for $r=1,4$ for each period. This procedure is repeated until $\tau=T-r$ is reached, producing a sequence of predictive densities for the verification period. Our initial estimation period ranges from $1979 \mathrm{q} 2$ to $\tau_{0}=2003 \mathrm{q} 4$. The hold-out sample consists of 40 observations, covering the time span from 2004q1 to $T=2013 \mathrm{q} 4$.

To investigate the accuracy of predictive densities, researchers have opted for a plethora of different loss functions. In this paper, we focus on the log predictive score (LPS), which has been motivated, for instance, in Geweke and Amisano (2010). It has the advantage that it is widely used and that it is a so-called proper scoring rule (Gneiting, 2008).

More specifically, the log predictive score at time $\tau$ is the $r$-step-ahead predictive density conditional on the estimated parameters and past data and evaluated at the actual outcome for time $\tau+r, x_{\tau+r}^{O}$ :

$$
\operatorname{LPS}\left(x_{\tau+r}^{O} \mid \mathcal{D}_{\tau}\right)=\log p\left(x_{\tau+r}=x_{\tau+r}^{O} \mid \mathcal{D}_{\tau}\right)
$$

Unfortunately, $p\left(x_{\tau+r}=x_{\tau+r}^{O} \mid \mathcal{D}_{\tau}\right)$ does not have a closed form solution for $r>1$ (Adolfson et al., 2007). We proceed like Adolfson et al. and assume that it can be approximated by a multivariate normal density whose parameters can be estimated from the predictive sample. The resulting approximation is given by

$$
\begin{aligned}
\widetilde{\operatorname{LPS}}\left(x_{\tau+r}^{O} \mid \mathcal{D}_{\tau}\right) \approx & -0.5\left[k \log (2 \pi)+\log \left|\bar{\Omega}_{\tau+r \mid \tau}\right|\right. \\
& \left.+\left(x_{\tau+r}^{O}-\bar{x}_{\tau+r \mid \tau}\right)^{\prime} \bar{\Omega}_{\tau+r \mid \tau}^{-1}\left(x_{\tau+r}^{O}-\bar{x}_{\tau+r \mid \tau}\right)\right]
\end{aligned}
$$

with $\bar{\Omega}_{\tau+r \mid \tau}$ denoting the posterior variance-covariance matrix and $\bar{x}_{\tau+r}$ the mean vector of the predictive density.

In our analysis, we also look at the forecast performance in terms of the predictive density for all variables of a specific type. To investigate the corresponding variable- 
specific LPS we have to integrate out the effects of all other variables. Under the assumption of a multivariate normal predictive density, the marginal distribution of a subset of variables can be obtained by dropping the (ir-)relevant rows and columns of $\bar{\Omega}_{\tau+r \mid \tau}, \bar{x}_{\tau+r}$, and $x_{\tau+r}^{O}$. Thus, computation of the LPS corresponding to variables of type $m$ also simply boils down to evaluating the density of a multivariate normal distribution. Formally, this implies replacing $\bar{x}_{\tau+r \mid \tau}, \bar{\Omega}_{\tau+r \mid \tau}$ and $x_{\tau+r}^{O}$ in equation (5.3) with $\bar{x}_{m, \tau+r \mid \tau}, \bar{\Omega}_{m, \tau+r \mid \tau}$ and $x_{m, \tau+r}^{O}$ where $x_{m, \tau+r}^{O}$ is a vector which consists exclusively of variables of type $m$. Likewise, $\bar{x}_{m, \tau+r \mid \tau}$ denotes the posterior mean of the predictive densities of variables of type $m$ and $\bar{\Omega}_{m, \tau+r \mid \tau}$ denotes the posterior variance-covariance matrix corresponding to type- $m$ variables. Note that by the same reasoning the variance and the mean of each of the $k$ marginal predictive densities are given by the proper elements of the main diagonal of $\bar{\Omega}_{\tau+r \mid \tau}$ and $\bar{x}_{\tau+r}$, say $\left[\bar{\Omega}_{\tau+r \mid \tau}\right]_{l l}$ and $\left[\bar{x}_{\tau+r}\right]_{l}$ for $l=1,2, \ldots, k$.

To analyze the source of the overall forecast performance in more detail, we make use of the following result. It is straightforward to decompose the log score of the joint predictive density into the sum of the log scores of the predictive marginal (normal) densities and the log score of the predictive (Gaussian) copula density. The first term can serve as a measure of how well each of the variables is forecast integrating out all other variables. ${ }^{16}$ The second term can serve as a measure of how well the dependence structure among all variables of the model is forecast. Formally, we have

$$
\begin{aligned}
\widetilde{L P S}_{\tau+r \mid \tau}\left(x_{\tau+r}^{O} \mid \mathcal{D}_{\tau}\right)= & \sum_{l=1}^{k} \log p\left(x_{l, \tau+r}^{O} \mid \mathcal{D}_{\tau}\right) \\
& +\log c\left(P^{-1}\left(x_{1, \tau+r}^{O} \mid \mathcal{D}_{\tau}\right), \ldots, P^{-1}\left(x_{k, \tau+r}^{O} \mid \mathcal{D}_{\tau}\right)\right)
\end{aligned}
$$

where $p\left(x_{l, \tau+r}^{O} \mid \mathcal{D}_{\tau}\right)$ denotes the predictive marginal density of the $l$ th variable evaluated at the final outcome and conditional on current information, $P\left(x_{l, \tau+r}^{O} \mid \mathcal{D}_{\tau}\right)$

\footnotetext{
${ }^{16}$ Using the unweighted sum over all marginal densities implies an equal weighting scheme across variables.
} 
denotes the corresponding $c d f$, and $c(\cdot)$ is the probability density function of the Gaussian copula.

\section{Empirical Results}

\subsection{Baseline Comparison: Average Forecast Accuracy}

As stated in the previous section, we use the log scores of the joint predictive densities to compare the forecast performance of different models from a multivariate perspective. Table 3 shows these average joint log predictive scores for the GVAR forecasts and our benchmark forecasts based on country-specific stochastic volatility BVAR models. It is evident from the results that the GVAR model outperforms the BVAR models in terms of forecast performance for both forecast horizons. This holds true for the overall joint predictive density as well as for the joint predictive densities of each variable group conditional on the forecasts for the respective other variable groups.

[Table 3 about here.]

The average log score of the overall predictive densities of 1-step-ahead forecasts is 314.6 for the GVAR model compared to 271.6 for the BVAR models. Similarly, for 4-steps-ahead forecasts the corresponding average log score for the GVAR model (169.6) is much higher than that of the BVAR models (123.8). ${ }^{17}$

Where do these gains come from? A priori, there are two possibilities: First, it is possible that the GVAR performs better, on average, in terms of providing good forecasts for the predictive marginal densities for each of the variables. Second, performance gains could stem from more accurate predictions for the dependence structure among the variables in the system. These two effects can be analyzed

\footnotetext{
${ }^{17}$ Note that we cannot formally test the statistical significance of the difference in accuracy by using the test proposed by Amisano and Giacomini (2007), which only applies for a rolling sample scheme during the out-of-sample forecast analysis. In this paper we conduct the forecasting exercise based on an "expanding" window, which is more frequently used among practitioners.
} 
based on the decomposition given in equation (5.4). A gain along the second dimension would not be very surprising because the collection of benchmark BVAR models does not model cross-country dependencies by assumption whereas the GVAR model is designed to capture such interactions. Looking at the second and third row of Table 3 reveals that the second effect does indeed drive the overall forecasting performance of the GVAR: the log score of the predictive copula density for the GVAR model is much higher for both forecast horizons than that of the BVAR model. Interestingly, the gains are much higher for the 4-steps-ahead forecasts (69.6) than for the short-term forecasts (42.5). ${ }^{18}$ At the same time, the log scores for the predictive marginal densities indicate that they do not contribute to the superior overall forecast performance of the GVAR model. On the contrary: the GVAR performance for a forecast horizon of 4 quarters is much weaker along this dimension relative to the benchmark. Thus, the bottom line seems to be that the increased number of parameters in the GVAR model leads to a deterioration of forecast performance in terms of marginal predictive distributions which is outweighed by the gains that are realized in terms of better predictions of the cross-country dependencies.

Further results (shown in the lower part of Table 3) indicate that these performance gains are not driven by improved GVAR forecasts of some variable types. By contrast, the GVAR outperforms forecasts from local, country-specific VARs for all macro-variables considered in this paper. Focusing, for instance, on the log score of the joint predictive density of all GDP variables of the sample conditional on the forecasts for the other variables reveals that the GVAR model provides better forecasts for this group of variables for the short forecast horizon (61.9 vs 59.0) and for the longer forecast horizon (27.2 vs. 22.0). The difference seems to be especially pronounced when focusing on the conditional joint predictive densities of the short-term interest rate $\left(i_{S}\right)$ and equity prices $(e q)$ respectively.

\footnotetext{
${ }^{18}$ The difference is even more astonishing when comparing the differences of the predictive log copula scores to the levels of the overall predictive log scores, which are much smaller for the 4-steps-ahead forecasts.
} 
Overall, the results point to strong evidence of the GVAR framework outperforming country-specific benchmark VAR forecasts by a great margin. More specifically, this result is driven by the better predictions of the cross-country dependencies between variables which is a salient feature of the GVAR framework.

\subsection{Performance Variation over Time}

There is empirical evidence that the predictive accuracy of forecast models fluctuates over time both in terms of absolute accuracy (which obviously varies because shocks of different sizes hit the economy at different times) and relative accuracy (when different models are compared). ${ }^{19}$

This is why we also investigate whether and, if so, how the relative forecast performance of the GVAR model varies over time. On the one hand it could be argued that the complexity of the GVAR model captures the dynamics that once in a while cause volatile business-cycle fluctuations - thus its relative forecast performance could be especially pronounced during turbulent times. On the other hand it is well known that simpler forecast models tend to outperform complexer models especially during volatile periods because they are able to adjust more quickly to structural change.

Figure 1 shows that the log predictive scores of both models indeed vary strongly over time, with large decreases of the log scores for both models standing out during the period of the Great Recession. Three other aspects are noteworthy. First, the joint log predictive score of the GVAR model is consistently higher than that of the BVAR models over all periods of the evaluation sample and for both forecast horizons. Second, the deterioration of the log predictive scores during the Great Recession is - not surprisingly - more moderate for the medium-term forecasts. Finally, the deterioration of the log predictive scores during the Great Recession is much more severe for the BVAR models than for the GVAR model. In other words,

\footnotetext{
${ }^{19}$ See, for instance, Del Negro et al. (2014) or Geweke and Amisano (2010).
} 
the relative forecast performance of the GVAR model increased during the Great Recession. Two features are likely to contribute to this finding. First, the GVAR model reflects information from countries that fall into the recession earlier than others, thus anticipating the economic slowdown in the other countries. Second, the multiple channels of cross-country interaction built into the GVAR model allow anticipating the synchronicity of events during a global downturn.

[Figure 1 about here.]

A decomposition of the log score of the joint predictive density for each forecasting period as described in equation (5.4) can be interpreted as a confirmation of the two hypotheses. Figure 2 shows that two effects are at play which explain the good relative performance during the Great Recession. First, the decline of log scores for the marginal predictive densities is not as sharp in case of the GVAR model as it is for the BVAR benchmark. Second and very interestingly, the GVAR log scores for the predictive copula density actually increase during the Great Recession while they slightly decline for the BVAR benchmark. Thus, it seems that non-systematic, idiosyncratic shocks played a smaller role during the global downturn, which enhances the benefit of using a GVAR model that captures the systematic dependencies across countries.

[Figure 2 about here.]

An analysis of the different groups of variables reveals some interesting similarities and differences (Figure 3). First, the log predictive scores for the variabletype-specific conditional joint densities are higher for the GVAR than for the BVAR models in all periods for all types of variables. ${ }^{20}$ Second, the forecast performance sharply falls during the Great Recession virtually across the board. Third, this fall in forecast performance is equal in magnitude for both types of models with two

\footnotetext{
${ }^{20}$ For the presentation of results we focus on the short-run forecasts. Results for the 4-stepsahead forecasts are very similar and available upon request.
} 
exceptions, namely the joint predictive distribution of short-term interest rates and of equity prices, which drops more sharply in the BVAR models than in the GVAR model. This indicates that the very large differences of average log predictive densities that were documented for short-term interest rates and equity prices in the previous section mainly reflect the strong forecasting record of the GVAR during times of economic crisis.

[Figure 3 about here.]

\subsection{A Closer Look at Regions in the GVAR}

Undoubtedly, the countries of our sample are very different with respect to how strongly they are integrated into the world economy and how strongly they drive the global business cycle. ${ }^{21}$ Therefore, we want to analyze the gains in terms of forecast performance from using the GVAR model for forecasting different regions. To keep things simple and straightforward, we split the sample into a group of advanced economies (AE) and a group of emerging economies (EE). ${ }^{22}$

Specifically, we set all trade weights, $w_{i j}$, equal to 0 if country $i$ is in a different country group than country $j$. All other trade weights are adjusted accordingly to sum to unity. In essence, this yields two separate regional GVAR models for advanced and emerging economies, respectively. These models take information about the interconnectedness of countries within each of the groups into account while neglecting any spillover effects from advanced to emerging economies, and vice versa. The analysis shows how relevant it is to use information from different country groups when the single aim is to forecast variables from a particular group of countries.

To measure this relevance, we report the difference of log predictive scores. Since at this point we focus on forecasting all variables from one particular country group,

\footnotetext{
${ }^{21}$ See, for instance, Kose et al. (2003) for an extensive exploration of the importance of the global business cycle for a wide range of countries.

${ }^{22}$ The group of AE comprises the 15 European countries and the 5 other developed economies. The remaining 16 countries form the group of EE.
} 
we use the joint log predictive score for this subset of variables once the predictions for the variables of the other country group have been integrated out from the overall joint predictive density. We compute this measure for the newly constructed regional GVAR model and subtract the corresponding log score for the conventional GVAR model. Thus, negative values indicate an inferior forecast performance of the regional GVAR models while positive values indicate that moving to the more parsimonious model actually improves the quality of forecasts.

Figure 4 shows the differences of log scores for both country groups and the two forecast horizons. Evidently, neither the regional GVAR models nor the GVAR model dominates the other model over all periods. Both country groups exhibit periods with negative and positive log score differences. It is striking that the gains from using a truly global model increases especially during the time of the Great Recession. ${ }^{23}$

[Figure 4 about here.]

Furthermore, looking at the average over time reveals that taking spillover effects across country groups into account is more important for business-cycle forecasts for emerging economies than for advanced economies. For the 1-step-ahead forecasts, the mean difference is -16.8 for advanced economies but -67.0 for emerging economies, i. e., switching off transmission channels between advanced and emerging economies leads to a much larger deterioration of short-term forecast performance for emerging economies relative to advanced economies. Likewise for 4-steps-ahead forecasts: the average forecast performance for advanced economies increases when moving from the GVAR to the regional GVAR model (mean log score difference of 26.7) while it decreases slightly for emerging economies (-18.9).

\footnotetext{
${ }^{23}$ This results is similar to the finding in section 6.2 , which showed that the GVAR model outperformed the country-specific BVAR models especially during the Great Recession.
} 


\section{Conclusion}

In this paper, we analyze the ability of the GVAR model to generate accurate joint predictive densities for all variables of the system. To this end, we estimate a Bayesian GVAR model with SSVS priors and stochastic volatility and perform an out-of-sample forecast analysis. Our GVAR specification allows for a computationally efficient estimation of the model - which is essential when dealing with such high dimensional multi-country models in a context that requires repeated estimation.

Our results suggest that GVAR forecasts consistently improve the joint log predictive score compared to benchmark forecasts that are based on country-specific stochastic volatility BVAR models. This result holds true for the entire evaluation period of our forecasting sample but especially so for the Great Recession when the GVAR outperforms the benchmark by a great margin. Thus, it seems that modelling cross-country linkages is particularly important during times of global economic turbulences. By using a decomposition of the joint predictive density into the marginal densities and a copula term, we show that the performance gains of the GVAR are exclusively driven by better predictions of the cross-country dependencies. This decomposition approach might be of independent interest also in other forecast evaluation setups.

We proceed by estimating two regional GVAR models for advanced and emerging economies, respectively. A forecast analysis based on these models indicates no deterioration of forecasts for advanced economies when emerging economies are excluded in the regional GVAR. By contrast, shutting down spillover effects from advanced to emerging economies significantly deteriorates the quality of forecasts for emerging economies. This implies that while advanced economies could be modeled more parsimoniously taking into account only within-region spillover effects, forecasts for emerging economies can be significantly improved by considering information from advanced economies. However, for both regions the truly global GVAR framework featuring all economies in the sample excels in terms of forecast accuracy during the 
Great Recession 2008/09. Thus, our results only partially confirm the evidence in Kose et al. (2012) who find no strong links between the business cycles of advanced and emerging economies, respectively.

Our findings suggest that there are clear gains from using GVAR models when the aim is to coherently forecast the economies of a range of countries. Modeling cross-country linkages seems to pay off relative to the use of country-specific benchmark models. Our results concerning the minor contribution of modeling emerging economies when forecasting advanced economies suggest that further gains in forecast performance could be achieved by properly trimming the bilateral weights that are used to link different countries. However, our results also suggest that this applies mostly during tranquil times and that a parsimonious GVAR might do worse when the world economy is hit by a truly global shock such as the Great Recession, which is in line with the evidence in Crespo Cuaresma et al. (2014a). We leave these issues for future research. 


\section{References}

Adolfson, Malin, Jesper Lindé, and Mattias Villani, "Forecasting performance of an open economy DSGE model," Econometric Reviews, 2007, 26 (2-4), $289-328$.

Amisano, Gianni and Raffaella Giacomini, "Comparing Density Forecasts via Weighted Likelihood Ratio Tests," Journal of Business $\&$ Economic Statistics, 2007, 25 (2), 177-190.

Assenmacher, Katrin, "Forecasting the Swiss Economy with a Small GVAR Model," in Filippo di Mauro and M. Hashem Pesaran, eds., The GVAR Handbook, Oxford University Press, 2013, pp. 244-254.

Bańbura, Marta, Domenico Giannone, and Lucrezia Reichlin, "Large Bayesian vector auto regressions," Journal of Applied Econometrics, 2010, 25 (1), 71-92.

Bauer, Andy, Robert A. Eisenbeis, Daniel F. Waggoner, and Tao Zha, "Forecast evaluation with cross-sectional data: The Blue Chip Surveys," Economic Review, 2003, (Q2), 17-31.

Brown, Philip J., Marina Vannucci, and Tom Fearn, "Bayesian wavelength selection in multicomponent analysis," Journal of Chemometrics, 1998, 12 (3), $173-182$.

__ _ _ and _ _ , "Multivariate Bayesian variable selection and prediction," Journal of the Royal Statistical Society: Series B (Statistical Methodology), 1998, 60 (3), 627-641.

Carriero, Andrea, George Kapetanios, and Massimiliano Marcellino, "Forecasting exchange rates with a large Bayesian VAR," International Journal of Forecasting, 2009, 25 (2), 400-417.

_ _ , Todd E. Clark, and Massimiliano Marcellino, "Common drifting volatility in large Bayesian VARs," 2012.

Cashin, Paul, Kamiar Mohaddes, Maziar Raissi, and Mehdi Raissi, "The 
differential effects of oil demand and supply shocks on the global economy," Energy Economics, 2014, 44 (C), 113-134.

Castrén, Olli, Stéphane Dées, and Fadi Zaher, "Stress-testing euro area corporate default probabilities using a global macroeconomic model," Journal of Financial Stability, 2010, 6 (2), 64-78.

Cesa-Bianchi, Ambrogio, "Housing Cycles and Macroeconomic Fluctuations: A Global Perspective," Journal of International Money and Finance, October 2013 2013, 37, 215-238.

Chudik, Alexander and M. Hashem Pesaran, "Theory and Practice of GVAR Modeling," CESifo Working Paper Series 4807, CESifo Group Munich 2014.

_ and Marcel Fratzscher, "Identifying the global transmission of the 2007-2009 financial crisis in a GVAR model," European Economic Review, April 2011, 55 (3), 325-339.

Clark, Todd E., "Real-time density forecasts from Bayesian vector autoregressions with stochastic volatility," Journal of Business 65 Economic Statistics, 2011, 29 (3).

Crespo Cuaresma, Jesús, Martin Feldkircher, and Florian Huber, "Forecasting with Bayesian Global Vector Autoregressive Models: A Comparison of Priors," Working Papers 189, Oesterreichische Nationalbank (Austrian Central Bank) 2014.

_, _ , and _ _ , "Forecasting with Bayesian Global Vector Autoregressive Models: A Comparison of Priors," Working Papers 189, Oesterreichische Nationalbank (Austrian Central Bank) March 2014.

de Waal, Annari, Renee van Eyden, and Rangan Gupta, "Do we need a global VAR model to forecast inflation and output in South Africa?," Working Papers 2013-46, University of Pretoria, Department of Economics 2013.

Dées, Stéphane, Filippo di Mauro, M. Hashem Pesaran, and L. Vanessa Smith, "Exploring the international linkages of the euro area: a global VAR 
analysis," Journal of Applied Econometrics, 2007, 22 (1).

_ , Sean Holly, M. Hashem Pesaran, and L. Vanessa Smith, "Long Run Macroeconomic Relations in the Global Economy," Economics - The OpenAccess, Open-Assessment E-Journal, 2007, 1 (3), 1-20.

Del Negro, Marco, Raiden B. Hasegawa, and Frank Schorfheide, "Dynamic Prediction Pools: an Investigation of Financial Frictions and Forecasting Performance," Unpublished manuscript 2014.

Diebold, Francis X., Jinyong Y. Hahn, and Anthony S. Tay, "Multivariate density forecast evaluation and calibration in financial risk management: High frequency returns on foreign exchange," Review of Economics \&6 Statistics, 1999, $81(4), 661-673$.

Doan, Thomas, Robert Litterman, and Christopher A. Sims, "Forecasting and conditional projection using realistic prior distributions," Econometric Reviews, 1984, 3 (1), 1-100.

Dovern, Jonas and Björn van Roye, "International Transmission and BusinessCycle Effects of Financial Stress," Journal of Financial Stability, 2014, 13 (1), $1-17$.

— and Florian Huber, "Global Prediction of Recessions," unpublished manuscript, Oesterreichische Nationalbank 2015.

Eickmeier, Sandra and Tim Ng, "How do credit supply shocks propagate internationally? A GVAR approach," European Economic Review, 2015, forthcoming.

Eisenbeis, Robert, Daniel Waggoner, and Tao Zha, "Evaluating Wall Street Journal survey forecasters: a multivariate approach," Working Paper 2002-8, Federal Reserve Bank of Atlanta 2002.

Eisenstat, Eric and Rodney W. Strachan, "Modelling Inflation Volatility," CAMA Working Papers 2014-68, Centre for Applied Macroeconomic Analysis, Crawford School of Public Policy, The Australian National University 2014.

Feldkircher, Martin, "A global macro model for emerging Europe," Journal of 
Comparative Economics, 2015, forthcoming.

_ a and Florian Huber, "The international transmission of US shocks - Evidence from Bayesian global vector autoregressions," European Economic Review, 2015, forthcoming.

Frühwirth-Schnatter, Sylvia and Helga Wagner, "Stochastic model specification search for Gaussian and partial non-Gaussian state space models," Journal of Econometrics, 2010, 154 (1), 85-100.

Galesi, Alessandro and Marco J. Lombardi, "External shocks and international inflation linkages," in Filippo di Mauro and M. Hashem Pesaran, eds., The GVAR Handbook: Structure and Applications of a Macro Model of the Global Economy for Policy Analysis, Oxford University Press, 2013, pp. 255-270.

George, Edward I., Dongchu Sun, and Shawn Ni, "Bayesian stochastic search for VAR model restrictions," Journal of Econometrics, 2008, 142 (1), 553-580.

Geweke, John and Gianni Amisano, "Comparing and evaluating Bayesian predictive distributions of asset returns," International Journal of Forecasting, 2010, $26(2), 216-230$.

Gneiting, Tilmann, "Editorial: Probabilistic forecasting," Journal of the Royal Statistical Society Series A, 2008, 171 (2), 319-321.

Greenwood-Nimmo, Matthew, Viet Hoang Nguyen, and Yongcheol Shin, "Probabilistic forecasting of output growth, inflation and the balance of trade in a GVAR framework," Journal of Applied Econometrics, 2012, 27 (4), 554-573.

Huber, Florian, "Density Forecasting using Bayesian Global Vector Autoregressions with Common Stochastic Volatility," Department of Economics Working Paper Series 179, WU Vienna University of Economics and Business August 2014.

Independent Evaluation Office of the International Monetary Fund (IEO), "IMF Forecasts: Process, Quality, and Country Perspectives," Evaluation Report, Washington, D.C. February 12, 2014. 
Kastner, Gregor and Sylvia Frühwirth-Schnatter, "Ancillarity-sufficiency interweaving strategy (ASIS) for boosting MCMC estimation of stochastic volatility models," Computational Statistics \& Data Analysis, 2014, 76, 408-423.

Koop, Gary M., "Forecasting with medium and large Bayesian VARs," Journal of Applied Econometrics, 2013, 28 (2), 177-203.

Kose, M. Ayhan, Christopher Otrok, and Charles H. Whiteman, "International Business Cycles: World, Region, and Country-Specific Factors," American Economic Review, 2003, 93 (4), 1216-1239.

_ , _ , and Eswar Prasad, "Global Business Cycles: Convergence Or Decoupling?," International Economic Review, 2012, 53 (2), 511-538.

Madigan, David and Jeremy York, "Bayesian graphical models for discrete data," International Statistical Review, 1995, 63, 215-232.

Müller-Dröge, Hans Christian, Tara M. Sinclair, and Herman O. Stekler, "Evaluating Forecasts of a Vector of Variables. A German Forecasting Competition," Working Paper, George Washington University 2014.

Pesaran, M. Hashem, Schuermann Til, and Scott M. Weiner, "Modeling Regional Interdependencies Using a Global Error-Correcting Macroeconometric Model," Journal of Business \& Economic Statistics, 2004, 22 (2), 129-162.

_ , Til Schuermann, and L. Vanessa Smith, "Forecasting economic and financial variables with global VARs," International Journal of Forecasting, 2009, $25(4), 642-675$.

Sinclair, Tara M. and Herman O. Stekler, "Examining the quality of early GDP component estimates," International Journal of Forecasting, 2013, 29 (4), $736-750$.

Smith, L. Vanessa, "Short- and Medium-Term Forecasting Using 'Pooling' Techniques," in Filippo di Mauro and M. Hashem Pesaran, eds., The GVAR Handbook, Oxford University Press, 2013, pp. 114-130.

Swanson, Norman R., "Comments on "Forecasting economic and financial vari- 
ables with global VARs"," International Journal of Forecasting, 2009, 25 (4), 697-702. 
Table 1: Country coverage of GVAR model

\begin{tabular}{lllll}
\hline Europe & Other Developed & Emerging Asia & Latin America & Mid-East and Africa \\
\hline Austria (AT) & Australia (AU) & China (CH) & Argentina (AR) & Turkey (TR) \\
Belgium (BE) & Canada (CA) & India (IN) & Brazil (BR) & Saudi Arabia (SA) \\
Germany (DE) & Japan (JP) & Indonesia (ID) & Chile (CL) & South Africa (ZA) \\
Spain (ES) & New Zealand (NZ) & Malaysia (MY) & Mexico (MX) & \\
Finland (FI) & United States (US) & Korea (KR) & Peru (PE) & \\
France (FR) & & Philippines (PH) & & \\
Greece (GR) & & Singapore (SG) & & \\
Italy (IT) & & Thailand (TH) & & \\
Netherlands (NL) & & & & \\
Portugal (PT) & & & & \\
Denmark (DK) & & & & \\
Great Britain (GB) & & & & \\
Switzerland (CH) & & & & \\
Norway (NO) & & & \\
Sweden (SE) & & & & \\
\hline
\end{tabular}

Notes: ISO-2 country codes in brackets. 
Table 2: Data description

\begin{tabular}{|c|c|c|c|c|c|}
\hline Variable & Description & Min. & Mean & Max. & Coverage \\
\hline$y$ & $\begin{array}{l}\text { Real GDP, average of } \\
2005=100 . \quad \text { Seasonally } \\
\text { adjusted, in logarithms. }\end{array}$ & 2.173 & 4.298 & 5.400 & $100 \%$ \\
\hline$\Delta p$ & $\begin{array}{l}\text { Consumer price inflation in } \\
\text { q-o-q terms. CPI seasonally } \\
\text { adjusted. }\end{array}$ & -0.157 & 0.027 & 1.790 & $100 \%$ \\
\hline$e$ & $\begin{array}{l}\text { Nominal exchange rate vis- } \\
\text { à-vis the U.S. dollar, de- } \\
\text { flated by national price lev- } \\
\text { els (CPI). }\end{array}$ & -7.591 & -2.818 & 5.459 & $97.2 \%$ \\
\hline$e q$ & $\begin{array}{l}\text { Equity prices deflated by } \\
\text { CPI.Seasonally adjusted, in } \\
\text { logarithms. }\end{array}$ & -6.927 & 3.698 & 5.857 & $100 \%$ \\
\hline$i_{S}$ & $\begin{array}{l}\text { Typically } 3 \text {-months-market } \\
\text { rates, rates per annum. }\end{array}$ & -1.006 & 0.190 & 52.360 & $94.4 \%$ \\
\hline$i_{L}$ & $\begin{array}{l}\text { Typically government bond } \\
\text { yields, rates per annum. }\end{array}$ & 0.000 & 0.077 & 0.306 & $61.1 \%$ \\
\hline poil & $\begin{array}{l}\text { Price of oil, seasonally ad- } \\
\text { justed, in logarithms. }\end{array}$ & - & - & - & - \\
\hline Trade flows & $\begin{array}{l}\text { Bilateral data on exports } \\
\text { and imports of goods and } \\
\text { services, annual data. }\end{array}$ & - & - & - & - \\
\hline
\end{tabular}

Notes: Summary statistics pooled over countries and time. The coverage refers to the cross-country availability per country, in \%. Data are from the IMF's IFS data base and national sources. Trade flows stem from the IMF's DOTS data base. For more details see the data appendix in Feldkircher (2015). 
Table 3: Average joint log predictive scores

\begin{tabular}{lrrrrr}
\hline & \multicolumn{2}{c}{ 1-step-ahead } & & \multicolumn{2}{c}{ 4-steps-ahead } \\
& GVAR & BVAR & & GVAR & BVAR \\
\cline { 2 - 3 } \cline { 5 - 6 } Overall & 314.576 & 271.608 & & 169.622 & 123.758 \\
$\quad$ Marginals & 270.791 & 270.326 & & 149.596 & 173.356 \\
\multicolumn{1}{c}{ Copula } & 43.785 & 1.281 & & 20.025 & -49.598 \\
\hline$y$ & 61.945 & 58.976 & & 27.176 & 22.002 \\
$\Delta p$ & 64.888 & 61.271 & & 35.159 & 32.319 \\
$i_{S}$ & 50.680 & 41.762 & & 17.770 & 10.323 \\
$i_{L}$ & 59.291 & 56.768 & & 26.967 & 24.125 \\
$e$ & 39.606 & 36.066 & & 18.491 & 13.857 \\
$e q$ & 27.948 & 15.465 & & -2.257 & -14.309 \\
\hline
\end{tabular}

Notes: Average log predictive scores over the hold-out sample. Joint and variable-specific log scores have been obtained by using the multivariate normal approximation to the predictive density as in Adolfson et al. (2007). Variable-specific log scores are computed by integrating out the effects of other variables. The scores labeled "Marginals" and "Copula" refer to the decomposition of the overall log predictive score presented in equation (5.4) 
Figure 1: Evolution of the joint log predictive score over time

(a) 1-step

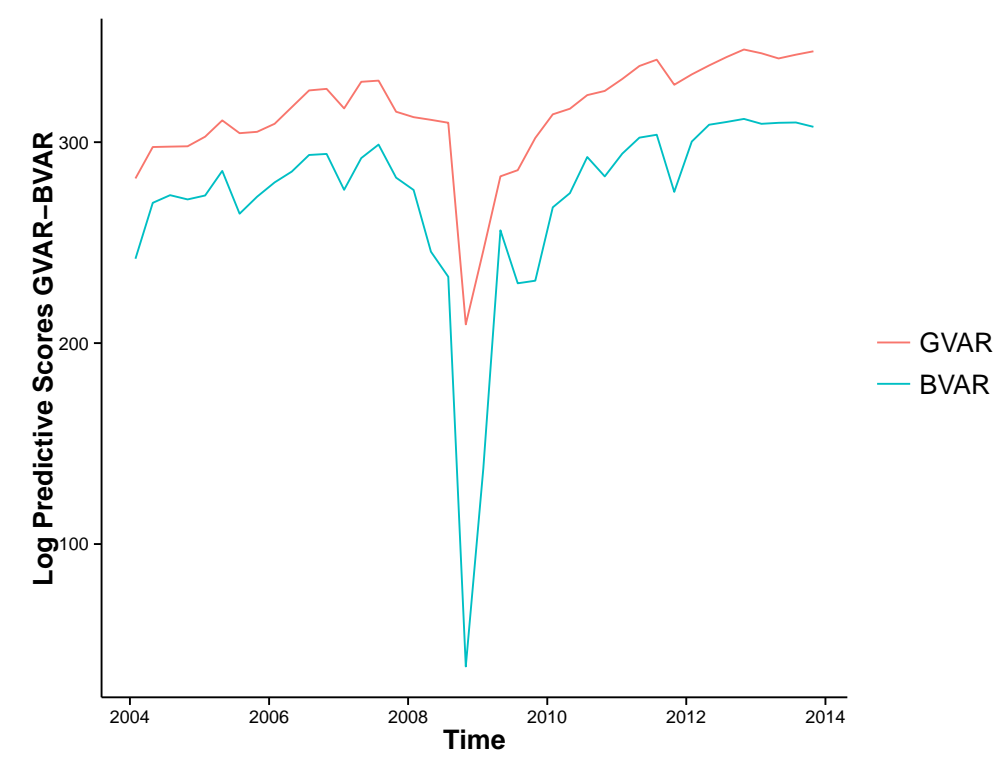

(b) 4-steps

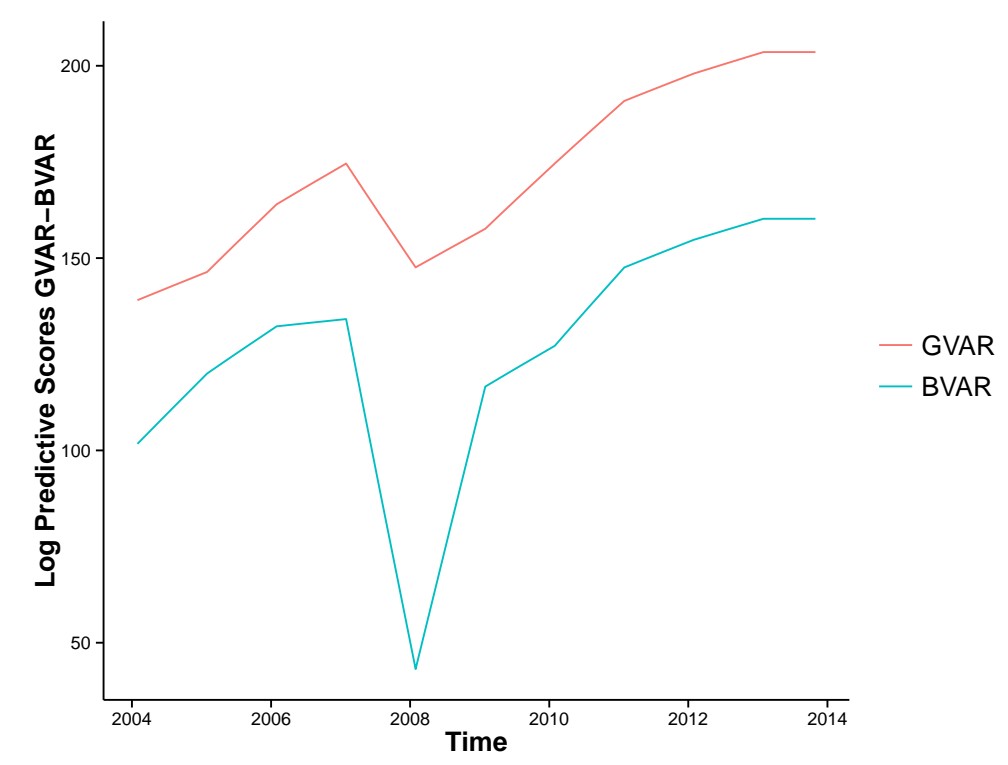

Notes: Evolution of the joint (for all variables and countries in the sytem) log predictive score for the hold-out sample. Results are based on the quadratic approximation to the log predictive score. 
Figure 2: Components of the joint log predictive score over time

(a) GVAR

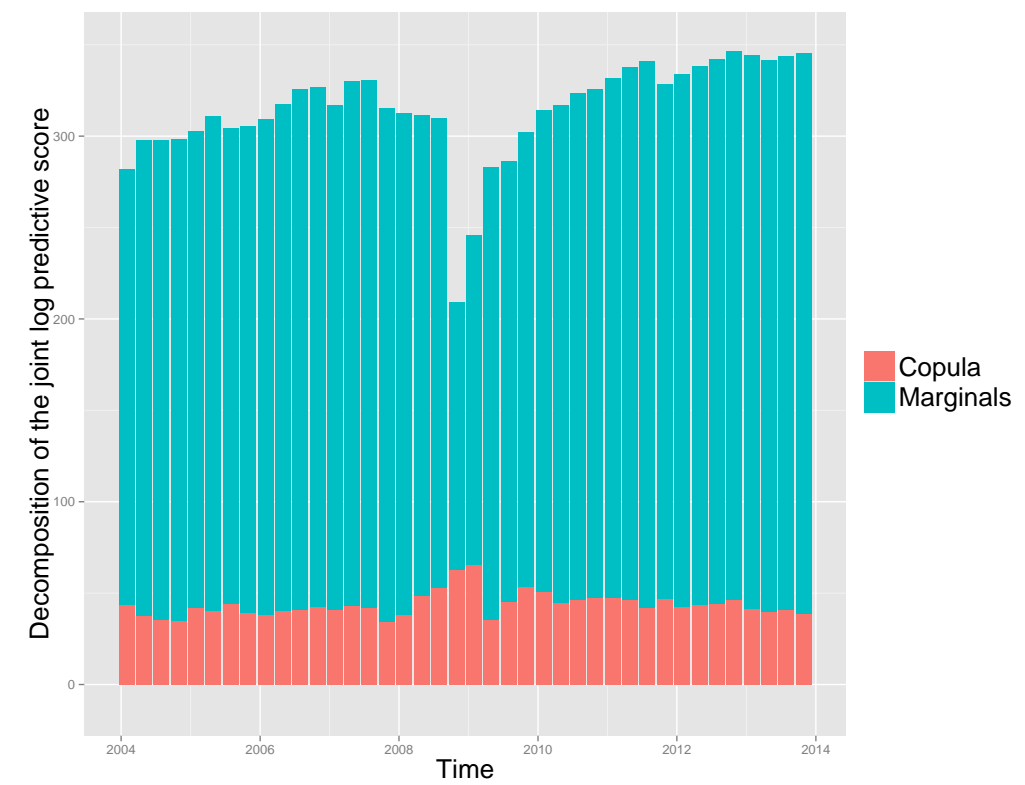

(b) BVAR

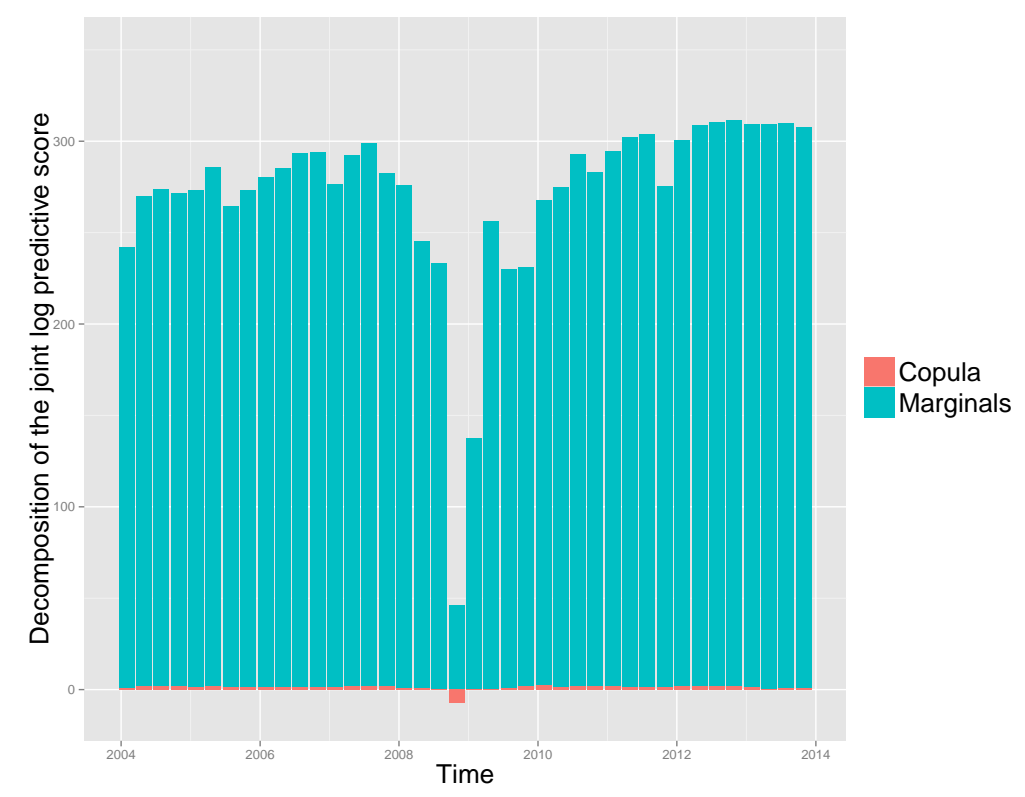

Notes: Evolution of both components of the (1-step-ahead) joint log predictive score (given in equation (5.4)) over the hold-out sample. Results are based on the quadratic approximation. 
Figure 3: Variable-specific log predictive scores over time

(a) GDP

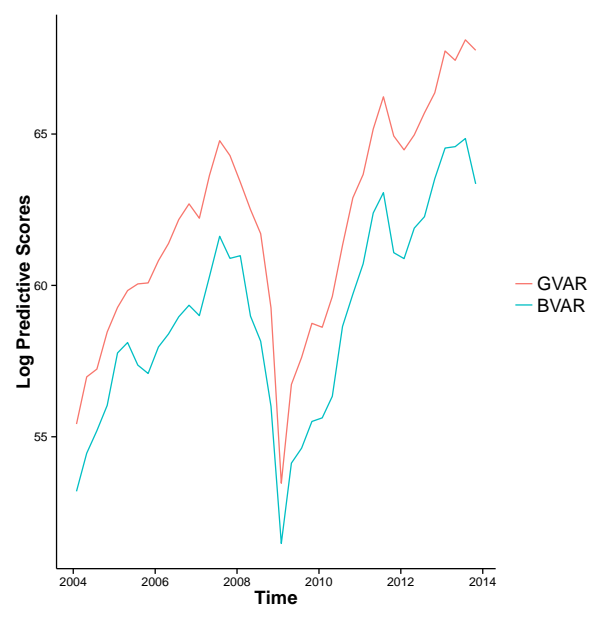

(c) Short-term interest rates

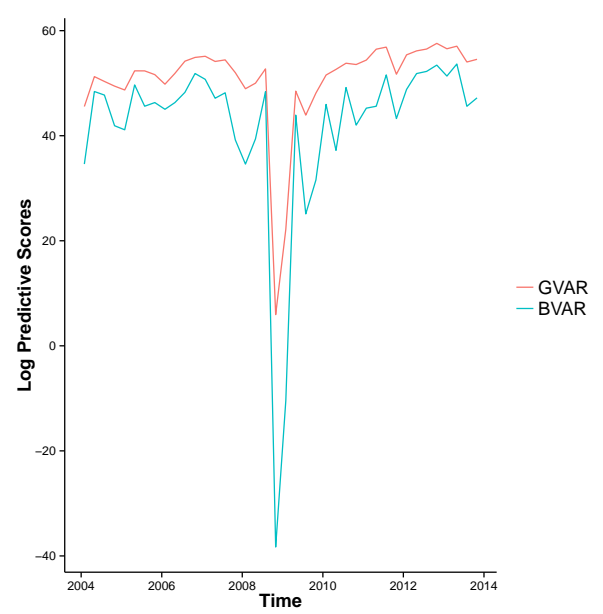

(e) Real exchange rate

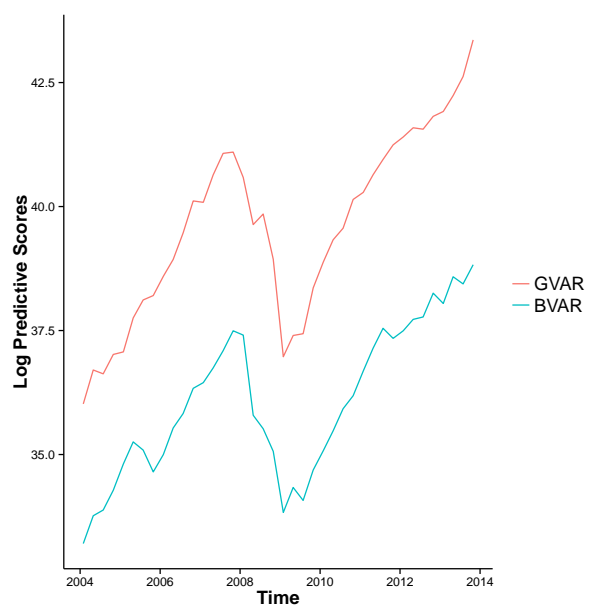

(b) Inflation

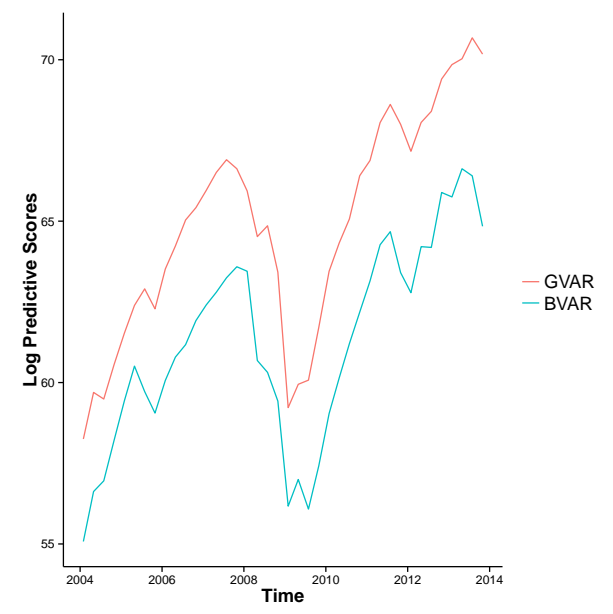

(d) Long-term interest rates

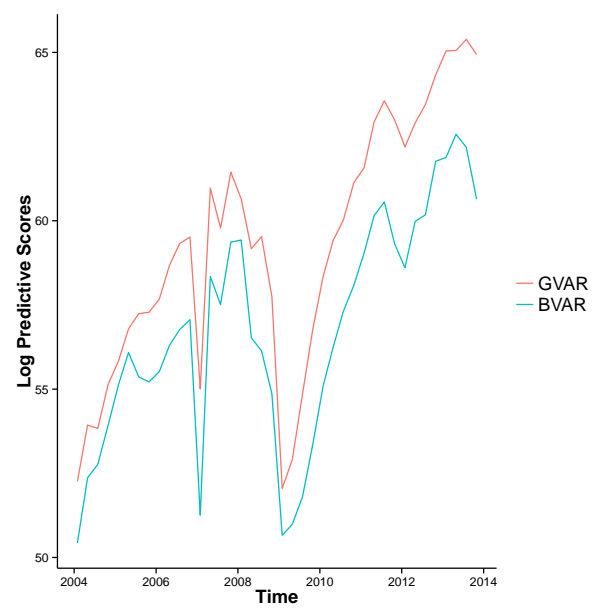

(f) Equity indices

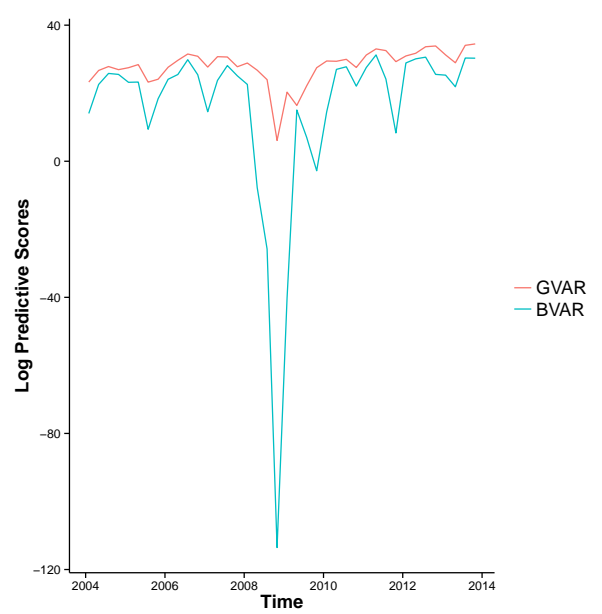

Notes: Evolution of the variable-specific (1-step-ahead) log predictive score for the hold-out sample. Results are based on the quadratic approximation to the log predictive score after integrating out the effects of other variables. 
Figure 4: Performance of regional GVAR models

(a) 1-step

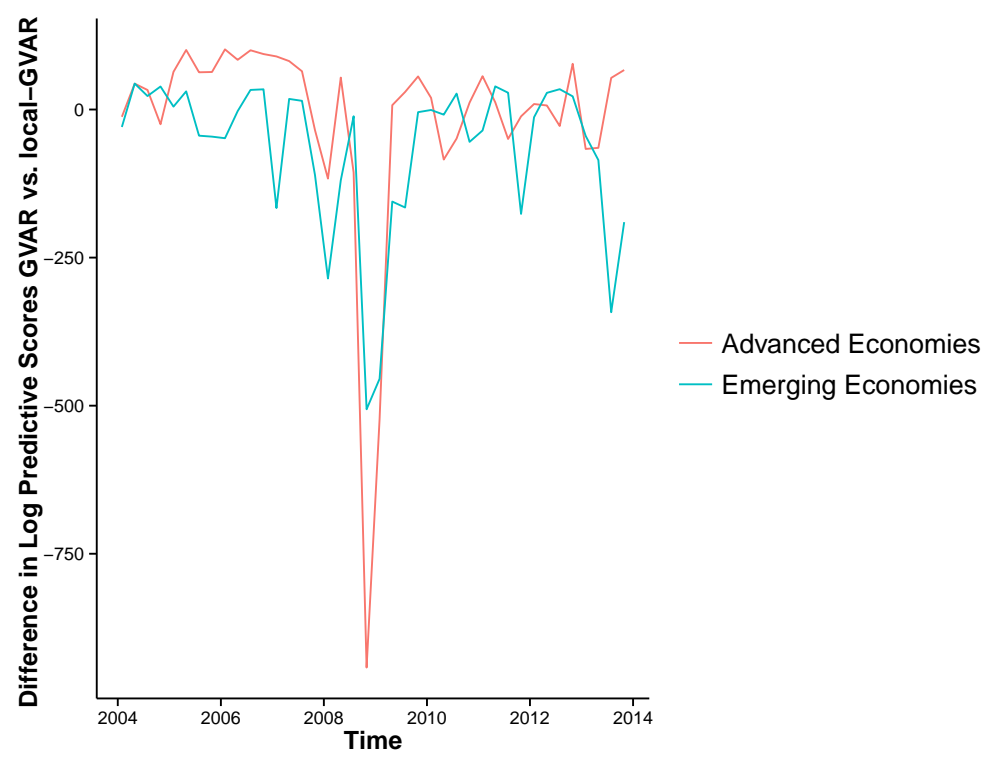

(b) 4-steps

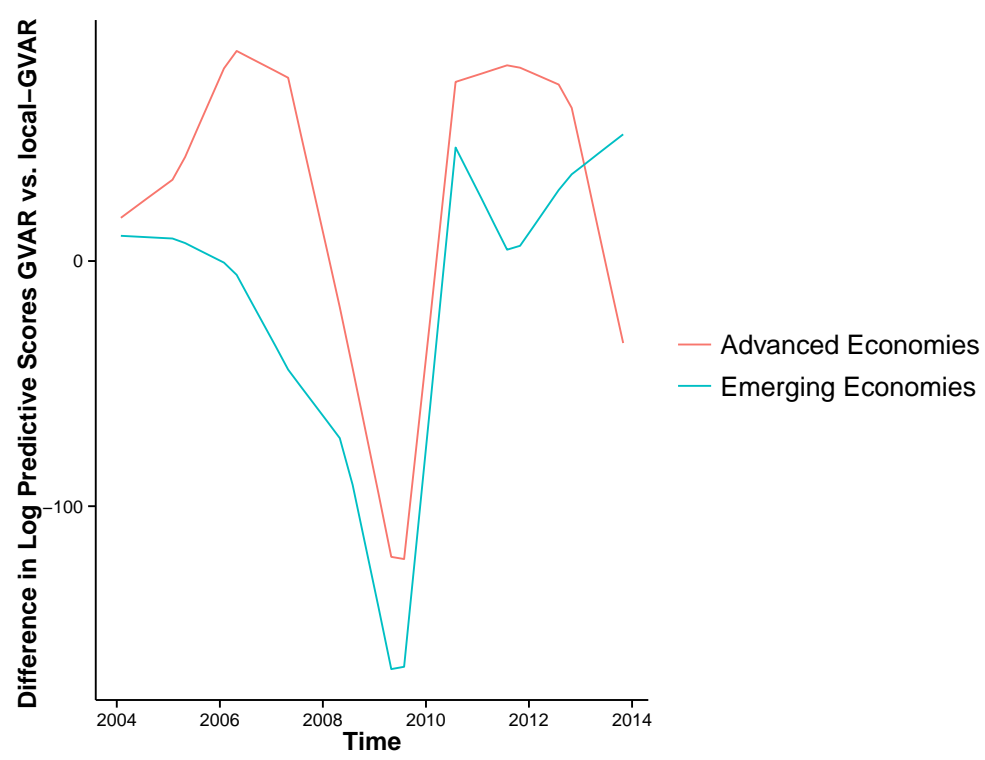

Notes: The figure shows the difference between the region-specific joint log predictive score for the regional GVAR models and the corresponding log score for the benchmark truly global GVAR. Region-specific joint log predictive scores are obtained by integrating out the effects of the other region. Positive values indicate that the regional GVAR models outperform the benchmark GVAR model. 



\section{Index of Working Papers:}

\begin{tabular}{|c|c|c|c|}
\hline $\begin{array}{l}\text { January 30, } \\
2009\end{array}$ & $\begin{array}{l}\text { Claudia Kwapil, } \\
\text { Johann Scharler }\end{array}$ & 149 & $\begin{array}{l}\text { Expected Monetary Policy and the } \\
\text { Dynamics of Bank Lending Rates }\end{array}$ \\
\hline $\begin{array}{l}\text { February 5, } \\
2009\end{array}$ & $\begin{array}{l}\text { Thomas Breuer, } \\
\text { Martin Janda ka, } \\
\text { Klaus Rheinberger, } \\
\text { Martin Summer }\end{array}$ & 150 & $\begin{array}{l}\text { How to find plausible, severe, and useful } \\
\text { stress scenarios }\end{array}$ \\
\hline $\begin{array}{l}\text { February } 11, \\
2009\end{array}$ & $\begin{array}{l}\text { Martin Schneider, } \\
\text { Christian Ragacs }\end{array}$ & 151 & $\begin{array}{l}\text { Why did we fail to predict GDP during the } \\
\text { last cycle? A breakdown of forecast errors } \\
\text { for Austria }\end{array}$ \\
\hline $\begin{array}{l}\text { February 16, } \\
2009\end{array}$ & $\begin{array}{l}\text { Burkhard Raunig, } \\
\text { Martin Scheicher }\end{array}$ & 152 & $\begin{array}{l}\text { Are Banks Different? Evidence from the } \\
\text { CDS Market }\end{array}$ \\
\hline $\begin{array}{l}\text { March 11, } \\
2009\end{array}$ & $\begin{array}{l}\text { Markus Knell, } \\
\text { Alfred Stiglbauer }\end{array}$ & 153 & $\begin{array}{l}\text { The Impact of Reference Norms on Inflation } \\
\text { Persistence When Wages are Staggered }\end{array}$ \\
\hline May 14,2009 & Tarek A. Hassan & 154 & $\begin{array}{l}\text { Country Size, Currency Unions, and } \\
\text { International Asset Returns }\end{array}$ \\
\hline May 14, 2009 & Anton Korinek & 155 & $\begin{array}{l}\text { Systemic Risk: Amplification Effects, } \\
\text { Externalities, and Policy Responses }\end{array}$ \\
\hline May 29, 2009 & Helmut Elsinger & 156 & $\begin{array}{l}\text { Financial Networks, Cross Holdings, and } \\
\text { Limited Liability }\end{array}$ \\
\hline July 20, 2009 & Simona Delle Chiaie & 157 & $\begin{array}{l}\text { The sensitivity of DSGE models' results to } \\
\text { data detrending }\end{array}$ \\
\hline $\begin{array}{l}\text { November 10, } \\
2009\end{array}$ & $\begin{array}{l}\text { Markus Knell } \\
\text { Helmut Stix }\end{array}$ & 158 & $\begin{array}{l}\text { Trust in Banks? } \\
\text { Evidence from normal times } \\
\text { and from times of crises }\end{array}$ \\
\hline $\begin{array}{l}\text { November 27, } \\
2009\end{array}$ & $\begin{array}{l}\text { Thomas Scheiber } \\
\text { Helmut Stix }\end{array}$ & 159 & $\begin{array}{l}\text { Euroization in Central, Eastern and South- } \\
\text { eastern Europe - New Evidence On Its } \\
\text { Extent and Some Evidence On Its Causes }\end{array}$ \\
\hline $\begin{array}{l}\text { January } 11 \\
2010\end{array}$ & $\begin{array}{l}\text { Jesús Crespo } \\
\text { Cuaresma } \\
\text { Martin Feldircher }\end{array}$ & 160 & $\begin{array}{l}\text { Spatial Filtering, Model Uncertainty and the } \\
\text { Speed of Income Convergence in Europe }\end{array}$ \\
\hline $\begin{array}{l}\text { March 29, } \\
2010\end{array}$ & Markus Knell & 161 & $\begin{array}{l}\text { Nominal and Real Wage Rigidities. } \\
\text { In Theory and in Europe }\end{array}$ \\
\hline
\end{tabular}




\begin{tabular}{|c|c|c|c|}
\hline May 31, 2010 & $\begin{array}{l}\text { Zeno Enders } \\
\text { Philip Jung } \\
\text { Gernot J. Müller }\end{array}$ & 162 & Has the Euro changed the Business Cycle? \\
\hline $\begin{array}{l}\text { August 25, } \\
2010\end{array}$ & $\begin{array}{l}\text { Marianna ervená } \\
\text { Martin Schneider }\end{array}$ & 163 & $\begin{array}{l}\text { Short-term forecasting GDP with a DSGE } \\
\text { model augmented by monthly indicators }\end{array}$ \\
\hline $\begin{array}{l}\text { September 8, } \\
2010\end{array}$ & $\begin{array}{l}\text { Sylvia Kaufmann } \\
\text { Johann Scharler }\end{array}$ & 164 & $\begin{array}{l}\text { Bank-Lending Standards, the Cost Channel } \\
\text { and Inflation Dynamics }\end{array}$ \\
\hline $\begin{array}{l}\text { September 15, } \\
2010\end{array}$ & Helmut Elsinger & 165 & $\begin{array}{l}\text { Independence Tests based on Symbolic } \\
\text { Dynamics }\end{array}$ \\
\hline $\begin{array}{l}\text { December 14, } \\
2010\end{array}$ & Claudia Kwapil & 166 & $\begin{array}{l}\text { Firms' Reactions to the Crisis and their } \\
\text { Consequences for the Labour Market. } \\
\text { Results of a Company Survey conducted in } \\
\text { Austria }\end{array}$ \\
\hline May 10,2011 & Helmut Stix & 167 & $\begin{array}{l}\text { Does the Broad Public Want to Consolidate } \\
\text { Public Debt? - The Role of Fairness and of } \\
\text { Policy Credibility }\end{array}$ \\
\hline May 11,2011 & $\begin{array}{l}\text { Burkhard Raunig, } \\
\text { Johann Scharler }\end{array}$ & 168 & $\begin{array}{l}\text { Stock Market Volatility, Consumption and } \\
\text { Investment; An Evaluation of the Uncertainty } \\
\text { Hypothesis Using Post-War U.S. Data }\end{array}$ \\
\hline May 23, 2011 & Steffen Osterloh & 169 & $\begin{array}{l}\text { Can Regional Transfers Buy Public } \\
\text { Support? Evidence from EU Structural } \\
\text { Policy }\end{array}$ \\
\hline May 23,2011 & $\begin{array}{l}\text { Friederike Niepmann } \\
\text { Tim Schmidt-Eisenlohr }\end{array}$ & 170 & $\begin{array}{l}\text { Bank Bailouts, International Linkages and } \\
\text { Cooperation }\end{array}$ \\
\hline $\begin{array}{l}\text { September 1, } \\
2011\end{array}$ & $\begin{array}{l}\text { Jarko Fidrmuc, } \\
\text { Mariya Hake, } \\
\text { Helmut Stix }\end{array}$ & 171 & $\begin{array}{l}\text { Households' Foreign Currency Borrowing in } \\
\text { Central and Eastern Europe }\end{array}$ \\
\hline $\begin{array}{l}\text { September 9, } \\
2011\end{array}$ & $\begin{array}{l}\text { Jürgen Eichberger, } \\
\text { Klaus Rheinberger, } \\
\text { Martin Summer }\end{array}$ & 172 & Credit Risk in General Equilibrium \\
\hline $\begin{array}{l}\text { October 6, } \\
2011\end{array}$ & Peter Lindner & 173 & $\begin{array}{l}\text { Decomposition of Wealth and Income using } \\
\text { Micro Data from Austria }\end{array}$ \\
\hline $\begin{array}{l}\text { October 18, } \\
2011\end{array}$ & Stefan Kerbl & 174 & $\begin{array}{l}\text { Regulatory Medicine Against Financial } \\
\text { Market Instability: } \\
\text { What Helps And What Hurts? }\end{array}$ \\
\hline
\end{tabular}




\begin{tabular}{|c|c|c|}
\hline $\begin{array}{l}\text { December 31, } \\
2011\end{array}$ & $\begin{array}{l}\text { Konstantins Benkovskis } \\
\text { Julia Wörz }\end{array}$ & 175 How Does Quality Impact on Import Prices? \\
\hline $\begin{array}{l}\text { January } 17, \\
2012\end{array}$ & Nicolás Albacete & $\begin{array}{ll}176 & \text { Multiple Imputation in the Austrian } \\
\text { Household Survey on Housing Wealth }\end{array}$ \\
\hline $\begin{array}{l}\text { January 27, } \\
2012\end{array}$ & $\begin{array}{l}\text { Gerhard Fenz, } \\
\text { Lukas Reiss, } \\
\text { Martin Schneider }\end{array}$ & $\begin{array}{l}177 \text { A structural interpretation of the impact of } \\
\text { the great recession on the Austrian } \\
\text { economy using an estimated DSGE model }\end{array}$ \\
\hline $\begin{array}{l}\text { July } 27 \\
2012\end{array}$ & Helmut Stix & $\begin{array}{l}178 \text { Why Do People Save in Cash? Distrust, } \\
\text { Memories of Banking Crises, Weak } \\
\text { Institutions and Dollarization }\end{array}$ \\
\hline $\begin{array}{l}\text { August 20, } \\
2012\end{array}$ & Markus Knell & $\begin{array}{l}179 \text { Increasing Life Expectancy and Pay-As- } \\
\text { You-Go Pension Systems }\end{array}$ \\
\hline $\begin{array}{l}\text { September 25, } \\
2012\end{array}$ & $\begin{array}{l}\text { Fabio Rumler, } \\
\text { Walter Waschiczek }\end{array}$ & $\begin{array}{l}180 \text { Have Changes in the Financial Structure } \\
\text { Affected Bank Protability? Evidence for } \\
\text { Austria }\end{array}$ \\
\hline $\begin{array}{l}\text { November 9, } \\
2012\end{array}$ & $\begin{array}{l}\text { Elisabeth Beckmann, } \\
\text { Jarko Fidrmuc, } \\
\text { Helmut Stix }\end{array}$ & $\begin{array}{l}181 \text { Foreign Currency Loans and Loan Arrears } \\
\text { of Households in Central and Eastern } \\
\text { Europe }\end{array}$ \\
\hline $\begin{array}{l}\text { June 10, } \\
2013\end{array}$ & Luca Fornaro & 182 International Debt Deleveraging \\
\hline $\begin{array}{l}\text { June 10, } \\
2013\end{array}$ & $\begin{array}{l}\text { Jenny Simon, } \\
\text { Justin Valasek }\end{array}$ & $\begin{array}{l}183 \text { Efficient Fiscal Spending by Supranational } \\
\text { Unions }\end{array}$ \\
\hline $\begin{array}{l}\text { July 24, } \\
2013\end{array}$ & $\begin{array}{l}\text { Thomas Breuer, Hans- } \\
\text { Joachim Vollbrecht, } \\
\text { Martin Summer }\end{array}$ & $\begin{array}{l}184 \text { Endogenous Leverage and Asset Pricing in } \\
\text { Double Auctions }\end{array}$ \\
\hline $\begin{array}{l}\text { September 23, } \\
2013\end{array}$ & Martin Feldkircher & 185 A Global Macro Model for Emerging Europe \\
\hline $\begin{array}{l}\text { September 25, } \\
2013\end{array}$ & $\begin{array}{l}\text { Martin Gächter, } \\
\text { Aleksandra Riedl }\end{array}$ & $\begin{array}{l}186 \text { One Money, One Cycle? The EMU } \\
\text { Experience }\end{array}$ \\
\hline $\begin{array}{l}\text { December 9, } \\
2013\end{array}$ & $\begin{array}{l}\text { Stefan Niemann, } \\
\text { Paul Pichler }\end{array}$ & 187 Collateral, Liquidity and Debt Sustainability \\
\hline $\begin{array}{l}\text { March 6, } \\
2014\end{array}$ & $\begin{array}{l}\text { Elisabeth Beckmann, } \\
\text { Helmut Stix }\end{array}$ & $\begin{array}{l}188 \text { Foreign currency borrowing and knowledge } \\
\text { about exchange rate risk }\end{array}$ \\
\hline
\end{tabular}




\begin{tabular}{llrl}
\hline March 10, & Jesús Crespo & 189 & Forecasting with Bayesian Global Vector \\
2014 & Cuaresma, & Autoregressive Models: \\
& Martin Feldkircher, & A Comparison of Priors \\
& Florian Huber &
\end{tabular}

\begin{tabular}{lll}
\hline $\begin{array}{l}\text { May 12, Claudia Steinwender } \\
2014\end{array}$ & $190 \begin{array}{l}\text { Information Frictions and the Law of One } \\
\text { Price: "When the States and the Kingdom } \\
\text { became United" }\end{array}$
\end{tabular}

\begin{tabular}{llll}
\hline $\begin{array}{l}\text { May 12, } \\
2014\end{array}$ & Saleem A. Bahaj & $191 \begin{array}{l}\text { Systemic Sovereign Risk: Macroeconomic } \\
\text { Implications in the Euro Area }\end{array}$ \\
\hline May 16, & John Bagnall, & $192 \begin{array}{l}\text { Consumer Cash Usage: A Cross-Country } \\
\text { Comparison with Payment Diary Survey } \\
\text { David Bounie, } \\
\text { Kim P. Huynh, }\end{array}$ & Data \\
& $\begin{array}{l}\text { Anneke Kosse, } \\
\text { Tobias Schmidt, } \\
\text { Scott Schuh and } \\
\text { Helmut Stix }\end{array}$ & \\
& & \\
&
\end{tabular}

\begin{tabular}{llrl}
\hline $\begin{array}{l}\text { May 19, } \\
2014\end{array}$ & $\begin{array}{l}\text { Konstantins Benkovskis } \\
\text { Julia Wörz }\end{array}$ & 193 & $\begin{array}{l}\text { "Made in China" - How Does it Affect } \\
\text { Measures of Competitiveness? }\end{array}$ \\
\hline $\begin{array}{l}\text { June 25, } \\
2014\end{array}$ & $\begin{array}{l}\text { Burkhard Raunig, } \\
\text { Johann Scharler and } \\
\text { Friedrich Sindermann }\end{array}$ & 194 & Do Banks Lend Less in Uncertain Times? \\
& Martin Feldkircher and & 195 & $\begin{array}{l}\text { The International Transmission of U.S. } \\
\text { Structural Shocks - Evidence from Global } \\
\text { Vector Autoregressions }\end{array}$ \\
\hline $\begin{array}{l}\text { July 28, } \\
2014\end{array}$ & Florian Huber & &
\end{tabular}

\begin{tabular}{|c|c|c|c|}
\hline $\begin{array}{l}\text { September 16, } \\
2014\end{array}$ & $\begin{array}{l}\text { Kim P. Huynh, } \\
\text { Philipp Schmidt- } \\
\text { Dengler, } \\
\text { Helmut Stix }\end{array}$ & 196 & $\begin{array}{l}\text { The Role of Card Acceptance in the } \\
\text { Transaction; Demand for Money }\end{array}$ \\
\hline $\begin{array}{l}\text { October 10, } \\
2014\end{array}$ & $\begin{array}{l}\text { Martin Brown, } \\
\text { Helmut Stix }\end{array}$ & 197 & $\begin{array}{l}\text { The Euroization of Bank Deposits in Eastern } \\
\text { Europe }\end{array}$ \\
\hline $\begin{array}{l}\text { October } 17 \\
2014\end{array}$ & $\begin{array}{l}\text { Ludmila Fadejeva, } \\
\text { Martin Feldkircher, } \\
\text { Thomas Reininger }\end{array}$ & 198 & $\begin{array}{l}\text { Spillovers from Euro Area and U.S. Credit } \\
\text { and Demand Shocks: Comparing Emerging } \\
\text { Europe on the Basis of a GVAR Model }\end{array}$ \\
\hline $\begin{array}{l}\text { December 18, } \\
2014\end{array}$ & Esther Segalla & 199 & $\begin{array}{l}\text { Shock Transmission through International } \\
\text { Banks: Austria }\end{array}$ \\
\hline $\begin{array}{l}\text { March 5, } \\
2015\end{array}$ & $\begin{array}{l}\text { Jonas Dovern, } \\
\text { Martin Feldkircher, } \\
\text { Florian Huber }\end{array}$ & 200 & $\begin{array}{l}\text { Does Joint Modelling of the World Economy } \\
\text { Pay Off? Evaluating Global Forecasts from a } \\
\text { Bayesian GVAR }\end{array}$ \\
\hline
\end{tabular}




\section{Call for Entries: \\ Visiting Research Program}

The Oesterreichische Nationalbank (OeNB) invites applications from external researchers for participation in a Visiting Research Program established by the OeNB's Economic Analysis and Research Department. The purpose of this program is to enhance cooperation with members of academic and research institutions (preferably post-doc) who work in the fields of macroeconomics, international economics or financial economics and/or with a regional focus on Central, Eastern and Southeastern Europe.

The OeNB offers a stimulating and professional research environment in close proximity to the policymaking process. Visiting researchers are expected to collaborate with the OeNB's research staff on a prespecified topic and to participate actively in the department's internal seminars and other research activities. They will be provided with accommodation on demand and will, as a rule, have access to the department's computer resources. Their research output may be published in one of the department's publication outlets or as an OeNB Working Paper. Research visits should ideally last between 3 and 6 months, but timing is flexible.

Applications (in English) should include

- a curriculum vitae,

- a research proposal that motivates and clearly describes the envisaged research project,

- an indication of the period envisaged for the research visit, and

- information on previous scientific work.

Applications for 2014/2015 should be e-mailed to eva.gehringer-wasserbauer@oenb.at by May 1, 2015.

Applicants will be notified of the jury's decision by mid-June. The following round of applications will close on November 1, 2015. 